\title{
Sulfoxonium ylide derived metal carbenoids in organic synthesis
}

\author{
Janakiram Vaitla*a \\ Annette Bayer*a \\ a Department of Chemistry, UiT - The Arctic \\ University of Norway, N-9037 Tromsø, \\ Norway. \\ Janakiray.vaitla@uit.no \\ annette.bayer@uit.no
}

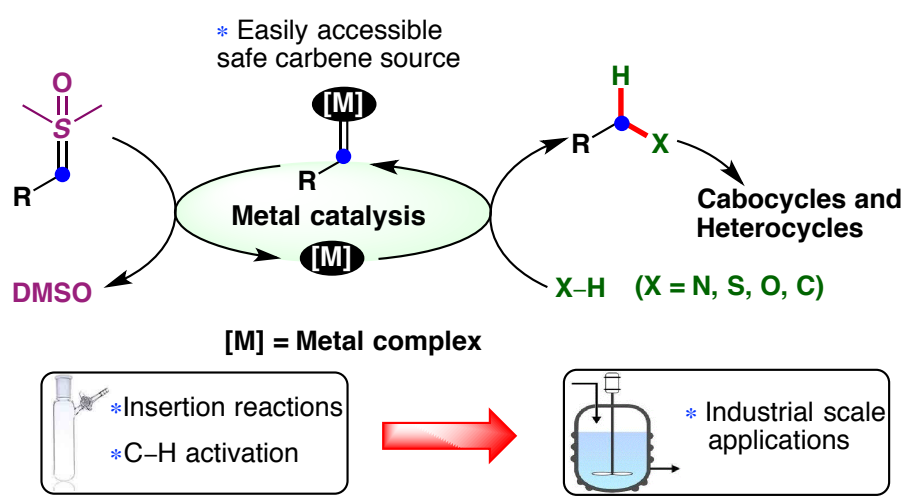

\section{Received:}

Accepted:

Published online: DOI:

Abstract As pioneered by Corey and Chaykovsky, sulfoxonium ylides have had widespread application in organic synthesis for more than a half century. In most of the reactions, sulfoxonium ylides were used to react with electrophiles. Under suitable reaction conditions these ylides can generate metal carbenoids and react with nucleophiles. By combining the typical reactivity of sulfoxonium ylides with transition metal catalysis, a growing number of investigations has expanded their application in organic synthesis. This review provides an update on the preparation of sulfoxonium ylides and their applications in carbenoid transfer reactions.

1. Introduction

2. Preparation of sulfoxonium ylides

3. Investigation for carbenoid formation from sulfoxonium ylide 4. $\mathrm{X}-\mathrm{H}(\mathrm{X}=\mathrm{N}, \mathrm{O}, \mathrm{S}, \mathrm{C})$ functionalization reactions

5. Polymerizaton of carbenoids generated from sulfoxonium ylides

6. Conclusion and perspective

Key words Sulfur ylides, metal carbenoids, transition metal catalysis, insertion reactions, $\mathrm{C}-\mathrm{H}$ activation, coupling reaction, heterocycles

\section{Introduction}

Metal carbenoids are important reaction intermediates ${ }^{1}$ for many organic transformations, such as cyclopropanations, ${ }^{2}$ cycloadditions, ${ }^{3} \mathrm{X}-\mathrm{H}(\mathrm{X}=\mathrm{C}, \mathrm{Si}, \mathrm{O}, \mathrm{S}, \mathrm{N})$ insertions, $^{4}$ ylide formations ${ }^{5}$ and cross-coupling reactions with different metals. ${ }^{6}$ Despite the fact that much progress has been achieved in carbenoid transfer reactions with diazo compounds, ${ }^{7}$ the toxicity and potential explosive character of diazo compounds afflicted their application in organic synthesis, ${ }^{8}$ in particular for large scale production. Therefore, surrogates of diazo compounds have been sought after. ${ }^{9}$
Sulfonium $\left(\mathrm{C}=\mathrm{SR}_{2}\right)$ and sulfoxonium $\left(\mathrm{C}=\mathrm{SOR}_{2}\right)$ ylides have been investigated as promising substitutes of diazo compounds for carbenoid transfer reactions. ${ }^{10}$ The stability and reactivity of sulfur ylides highly depend on the substituents adjacent to the carbanion of the ylide, thus, electron withdrawing groups stabilize the sulfur ylides and lead to more practical, benchstable reagents. ${ }^{11}$ The reactivity of sulfoxonium ylide derived carbenoids differ from sulfonium ylide derived carbenoids. For example, sulfonium ylide derived carbenoids underwent cyclopropanataion with non-activated alkenes, while stabilized sulfoxonium ylides failed to generate carbenoids under similar reaction conditions. ${ }^{12}$ In contrast, sulfoxonium ylide derived carbenoids inserted into $\mathrm{X}-\mathrm{H}(\mathrm{X}=\mathrm{C}, \mathrm{N}, \mathrm{O}, \mathrm{S})$ bonds of nucleophiles (Scheme 1), whereas to date no sulfonium ylide derived carbenoids has been successfully employed for insertion reactions. Significantly, the by-products (sulfoxides) of carbenoid transformation of sulfoxonium ylides are less toxic, non-volatile, and odorless compare to the by-products (sulfides) of sulfonium ylide derived carbenoid reactions. More recently, increased interest has focused on the carbenoid transformations of sulfoxonium ylides.

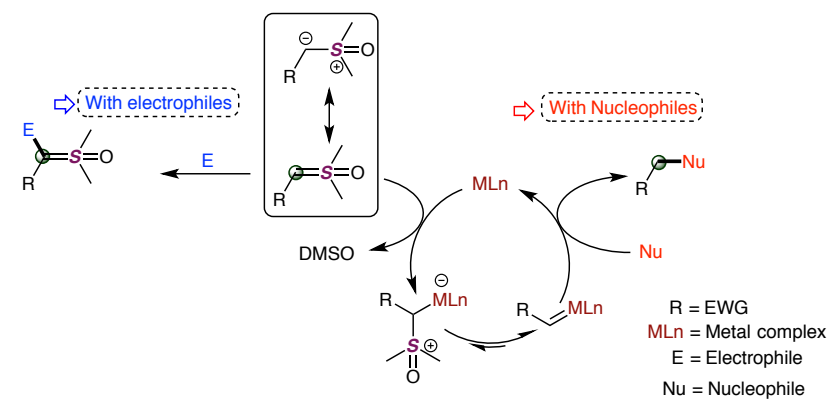

Scheme 1: Reactivity of sulfoxonium ylides with electrophiles under metal free conditions and with nucleophiles under metal catalysed conditions

In particular, the aim of this short review is to present the chemistry of metal carbenoids generated from sulfoxonium 
ylides, while showcasing their remarkable features through the recent developments.

\section{Preparation of Sulfoxonium Ylides}

The first synthesis of a sulfoxonium ylide was described in 1962 by Corey and Chaykovsky. ${ }^{13}$ They described the synthesis of dimethylsulfoxonium methylide $\mathbf{1}$ by the reaction of trimethylsulfoxonium iodide or chloride with sodium hydride in DMSO. The solution of dimethylsulfoxonium methylide $\mathbf{1}$ is unstable at $\mathrm{rt}$, however it is stable in THF solvent for several months in an inert atmosphere at $0^{\circ} \mathrm{C}$.

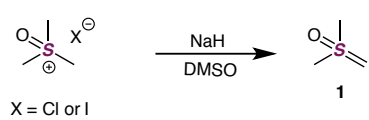

\section{Fig 1: Dimethylsulfoxonium methylide}

In general, sulfoxonium ylides can be prepared by four methods: (1) nucleophilic addition of methylide 1 to acid derivatives, (2) conjugate addition of $\mathbf{1}$ to alkynes containing elctron withdrawing groups, (3) conjugate addition of $\mathbf{1}$ to $\beta$-chloro substituted unsaturated ketones or imidoyl chlorides and (4) addition of sulfoxides to metal carbenoids.

\subsection{Addition of methylide 1 to acid derivatives.}

The first report of a stable sulfoxonium ylide was described by Corey and Chaykovsky in $1964 .{ }^{14}$ The treatment of benzoyl chloride with methylide 1 in THF at $25^{\circ} \mathrm{C}$ for $1 \mathrm{~h}$ led to stable $\alpha-$ keto sulfoxonium ylide in $92 \%$ yield (Scheme 2a). Similarly, the direct addition of methylide $\mathbf{1}$ to various acid chlorides, ${ }^{15}$ alkyl chloroformates, ${ }^{16}$ acid anhydrides, ${ }^{15 b}$ and phenyl isocyanates ${ }^{15 b}$ led to respective $\alpha$-keto sulfoxonium ylides.

a) Corey and Chaykovsky
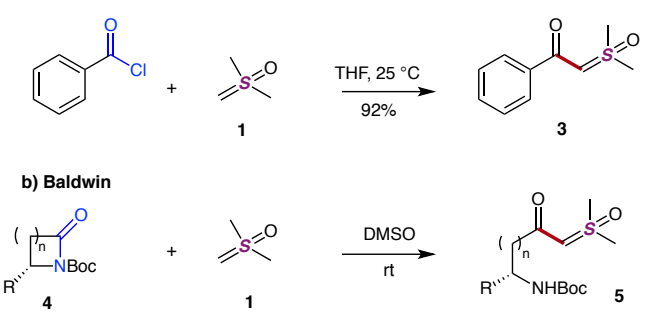

5a, $\mathrm{n}=1, \mathrm{R}=\mathrm{COOBn}(97 \%)$ $5 \mathbf{b}, \mathrm{n}=2, \mathrm{R}=\mathrm{COOCHPh}_{2}(97 \%)$

Scheme 2: Synthesis of sulfoxonium ylides from acid derivatives

In 1993, Baldwin et al. synthesized sulfoxonium ylide derivatives of chiral $\alpha$-amino acids by treatment of methylide $\mathbf{1}$ with lactams 4 in excellent yields and no epimerization was observed (Scheme 2b). ${ }^{12,17}$

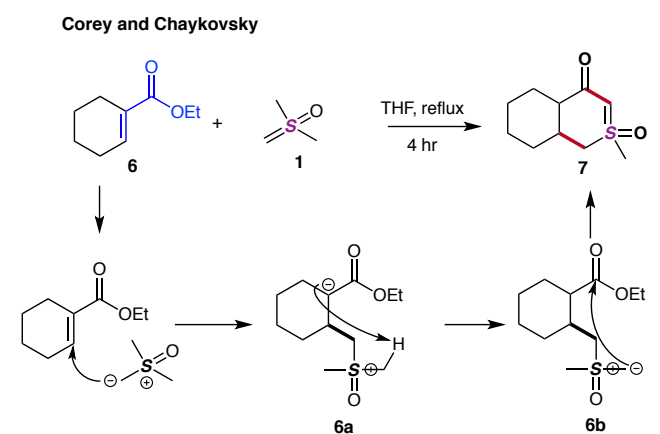

Scheme 3: Synthesis of cyclic sulfoxonium ylides
Notably, Corey and Chaykovsky observed that the reaction of methylide 1 with $\alpha, \beta$-unsaturated ethyl esters provided the 6membered cyclic sulfoxonium ylide 7. Possibly, the reaction proceeds via conjugate addition of methylide $\mathbf{1}$ to the unsaturated ester followed by a proton exchange generates sulfoxonium ylide $\mathbf{6 b}$ which undergo intramolecular cyclization to give 7 (Scheme 3). ${ }^{14}$

\subsection{Addition of methylide 1 to alkynes containing elctron} withdrawing groups.

In 1965, Trost's group reported for the synthesis of sulfoxonium ylide 9a (Scheme 4). Originally, the authors attempted the synthesis of cyclopropenes, however, the reaction of methylide $\mathbf{1}$ with propiolate derivates 8a provided dimethylsulfoxonium3-ethoxycarbonyl-2-phenylallylides 9a. ${ }^{18}$ Subsequently, Ide and Kishide further extended the scope of this reaction with various aryl substituted ethyl propiolates ${ }^{19}$

$$
\text { Trost, } 1965 \text { and Ide, } 1966
$$
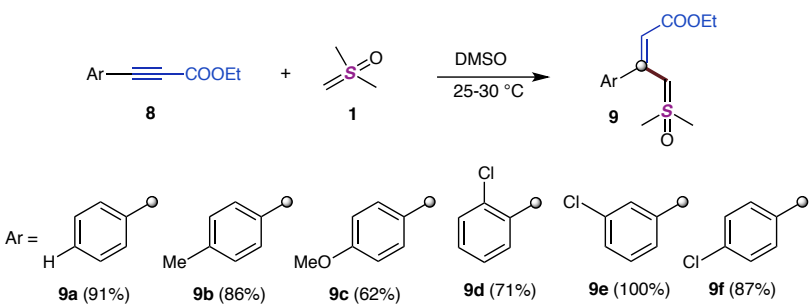

9e $(100 \%) \quad$ 9f $(87 \%)$

2.3. Addition of methylide 1 to $\beta$-chloro substituted $\alpha, \beta$ unsaturated ketones or imidoyl chlorides.

\subsubsection{From $\beta$-chloro substituted unsaturated ketones.}

The reaction of methylide $\mathbf{1}$ with $\beta$-chloro substituted unsaturated ketones such as 3-chlorocyclohex-2-enone (10a), ${ }^{20}$ 3-chloro-2-methyl-2-cyclo-hexene-l-one (10b), ${ }^{21}$ 3-chloro2-methyl-2-cyclopenten-1-one (10c), ${ }^{22}$ and 3-chloro-5,5dimethylcyclohex-2-enone $(\mathbf{1 0 d})^{23}$ provided corresponding vinyl sulfoxonium ylides 11a-d (Scheme 5). The mechanism of the reaction proceeds via conjugate addition of methylide $\mathbf{1}$ to the $\beta$-carbon of the unsaturated ketones, followed by elimination of chloride to provide the sulfoxonium ylides $\mathbf{1 1}$.

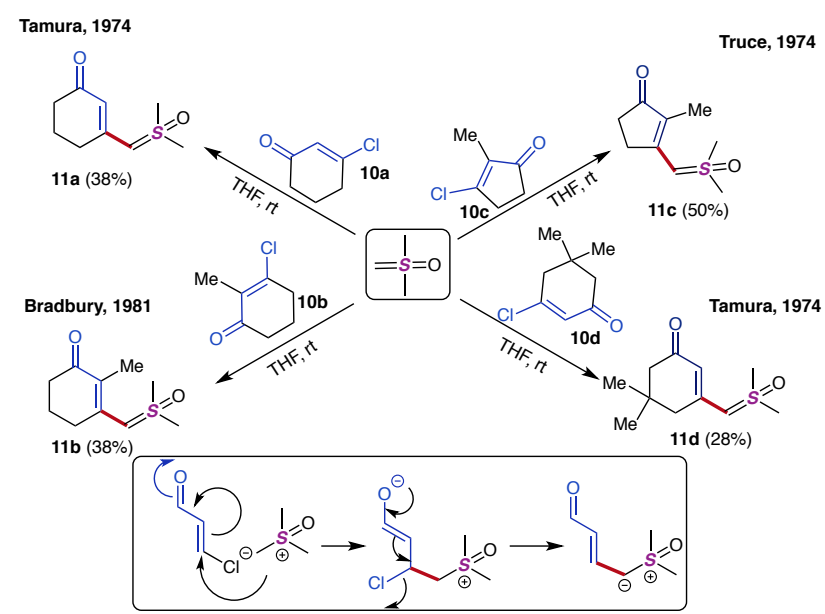

Scheme 5: Synthesis of sulfoxonium ylides from $\beta$-chloro substituted unsaturated ketones

2.3.2 From chloropyrimidines and 3-chloro benzothiozoles. 
Similarly, treatment methylide $\mathbf{1}$ with 2 -chloropyrimidine $\mathbf{1 2 a},{ }^{24}$ 2-chloro-4,6-dimethylpyrimidine 12b, ${ }^{25}$ 3-chlorobenzothiazole 1,1-dioxide $\mathbf{1 2} \mathbf{c}^{24}$ and 4-chloropyrimidine $\mathbf{1 2} \mathbf{d}^{26}$ resulted in the formation of corresponding sulfoxonium ylides 13a-d (Scheme 6). The reaction is initiated by the addition of methylide $\mathbf{1}$ to the imidoyl chloride followed by elimination of chloride.

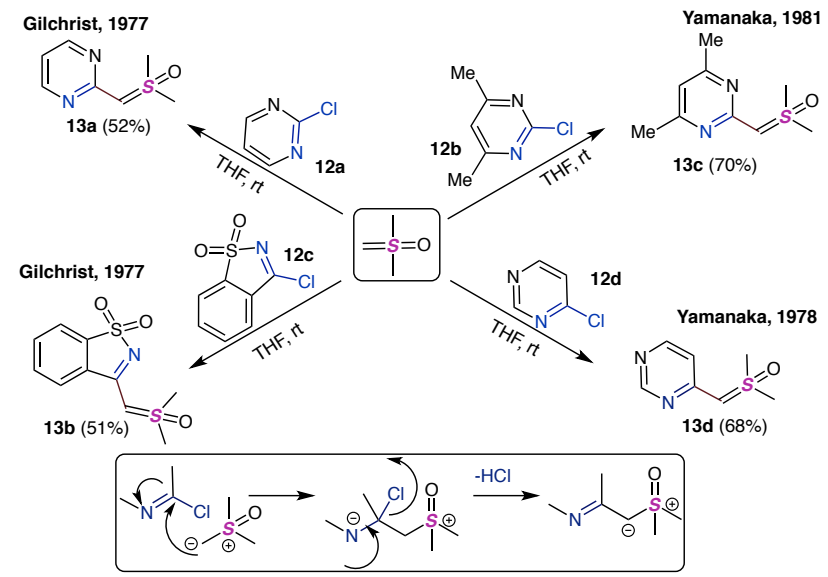

Scheme 6: Synthesis of sulfoxonium ylides from imidoyl chlorides and chloropyridmidines

\subsection{From metal carbenoids:}

As evident from the results compiled in previous section, dimethylsulfoxonium ylide is the only source to efficiently access stable sulfoxonium ylides. Despite the convenience of this direct approach, requirement of strong basic conditions (NaH or potassium tert-butoxide) is the major drawback to expand its utility. Alternatively, The reaction of lone pair of sulfoxide with metal carbenes which is generated from decomposition of diazo compounds or iodonium ylides also lead to the sulfoxonium ylide.

$$
\text { c) }
$$

\section{Scheme 7: Synthesis of sulfoxonium ylides from diazo compounds}

In 1969, Ando et al., synthesized sulfoxonium ylides via thermal or photochemical decomposition of diazo compounds (Scheme $7 \mathrm{a}$. The authors observed that in the presence of copper catalysed thermal conditions, the yields of the sulfoxonium ylides were better than photolytic conditions. ${ }^{27}$ The generation of carbenoids by transition metal-catalysed decomposition of diazo compounds is often more efficient than by photolysis and allows the carbenoids to be generated under mild reaction conditions. ${ }^{7 \mathrm{~d}}$ In 1970, Dost reported the use of copper and silver salts for the decomposition of diazo compounds to provide sulfoxonium ylides (Scheme 7b), ${ }^{28}$ whereas Moody's group studied the use of rhodium catalysts for intramolecular transformations (Scheme 7c). ${ }^{29}$ Among the transition metals tested, rhodium catalysts were proven most efficient for the conversion of diazo compounds to sulfoxonium ylides.

The preparation of sulfoxonium ylides by metal-catalysed decomposition of iodonium ylides was also investigated. In 2012, Zhdankin group developed a highly soluble iodonium ylide 21, which was transformed to a rhodium carbenoid and reacted with dimethyl sulfoxide (Scheme 8a). ${ }^{30}$ In 2017, Bayer and coworkers reported a direct approach for the synthesis of sulfoxonium ylides from malonates and sulfoxides (Scheme 8b). The nucleophilic carbon of $\mathbf{2 2}$ was converted to an electrophilic rhodium carbenoid via an in situ generated iodonium ylide, which was decomposed with a $\mathrm{Rh}$ (II) catalyst, and the rhodium carbenoid was trapped by sulfoxide to generate the sulfoxonium ylide 23.

a) Zhdankin, 2012<smiles>COC(=O)C(=Ic1ccccc1OC)C(=O)OC</smiles>

b) Bayer, 2017
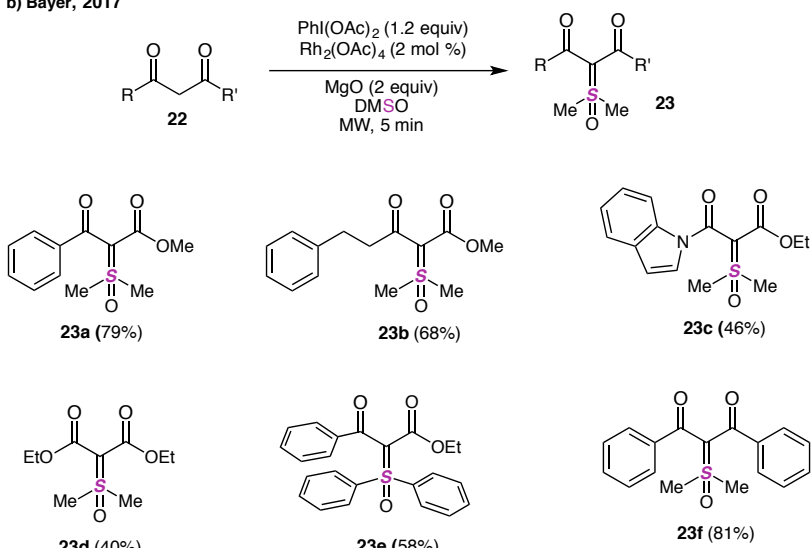

23d (40\%)

23e $(58 \%)$

$23 f(81 \%)$

$$
\begin{aligned}
& \text { reaction with } \mathrm{Ph}_{2} \mathrm{SO} \text { using 1,2-DCE as } \\
& \text { solvent }
\end{aligned}
$$
solvent

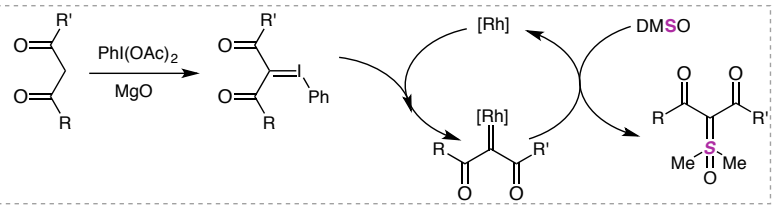

Scheme 8: Synthesis of sulfoxonium ylides from iodonium ylides

This method allowed for the preparation of a wide range of sulfoxonium ylides in moderate to good yields (40-81\%) under short reaction times (MW, 5-10 min) or 12-16 h at rt. ${ }^{31}$ Although iodonium ylides are safe alternatives for diazo compounds in the synthesis of sulfoxonium ylides, two acceptor groups adjacent to the ylide are required. With only one acceptor group generation of the iodonium ylide was not successful. ${ }^{31}$
3. Investigations of carbenoid formation from sulfoxonium ylides


The first evidence of carbenoid generation from sulfoxonium ylides was revealed by Corey and Chakovsky. ${ }^{14}$ The photochemical irradiation of $\alpha$-ketosulfoxonium ylide $\mathbf{3}$ under ultraviolet light at $253 \mathrm{~nm}$ in methanol or water led to $\mathrm{C}=\mathrm{S}$ bond scission followed by rearrangement to give ester $\mathbf{2 4}$ or acid $\mathbf{2 5}$ respectively (Scheme 9). These products were analogous to the products afforded by the Arndt-Eistert homologation, which proceeds via the rearrangement of an acyl carbenoid to a ketene. Thus, the formation of rearranged products $\mathbf{2 4}$ and $\mathbf{2 5}$ indicates that an acyl carbenoid is a viable intermediate in the observed reaction.
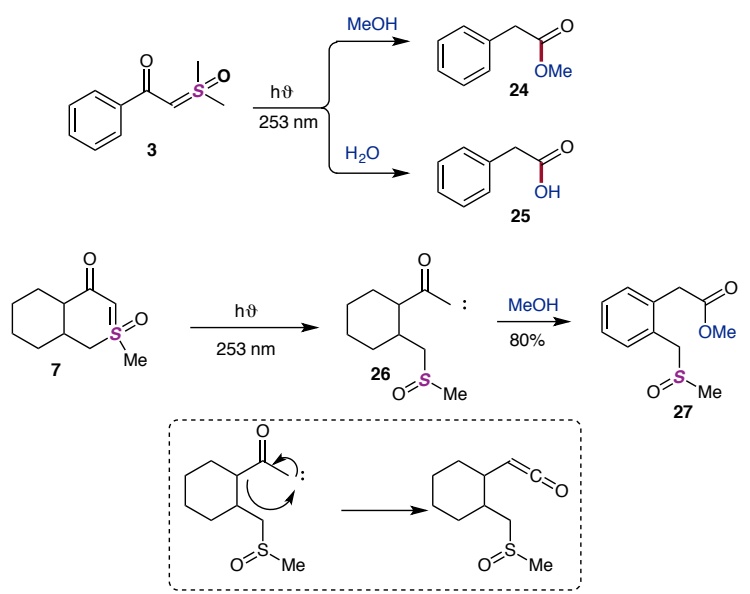

Scheme 9: Evidence for carbenoid generation from sulfoxonium ylides under photochemical conditions.

Recently, the groups of Mangion ${ }^{32}$ and Hopmann ${ }^{33}$ independently investigated iridium carbenoid derived from sulfoxonium ylides by NMR spectroscopy. Although, the metal carbenoid could not be directly detected by NMR, slow liberation of DMSO $\left({ }^{1} \mathrm{H}\right.$ NMR peak at $2.62 \mathrm{ppm}$ ) over time and dimerization of the ylide 3 as shown in Scheme 10, supported generation of the carbenoid. ${ }^{34}$
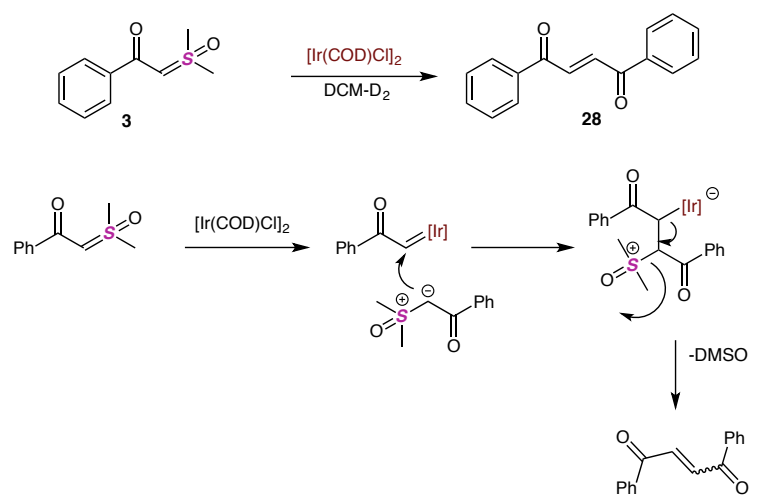

Scheme 10: Metal carbenoid mediated dimerization of sulfoxonium ylide

\section{4. $X-H(X=N, O, S, C)$ functionalization reactions}

Transition-metal catalysed insertion of carbenoids into $\mathrm{X}-\mathrm{H}(\mathrm{X}=$ $\mathrm{N}, \mathrm{O}, \mathrm{S}, \mathrm{C}$, etc.) bonds is an efficient tool for the construction of carbon-carbon and carbon-hetero atom bonds, which are ubiquitous motifs of organic molecules. ${ }^{35}$ Owing to the mild reaction conditions and high efficiency, metal-catalysed $\mathrm{X}-\mathrm{H}$ insertion reactions using diazo-derived carbenoids have been widely utilized in chemical synthesis in the past decades.
A

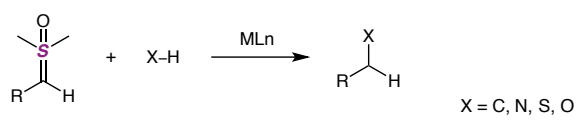<smiles>[R]C[SH](C)(C)=O</smiles>

C: via C-H activation

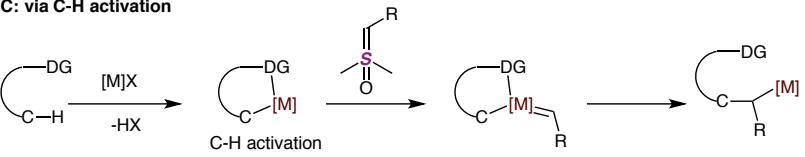

D: via Ylide formation

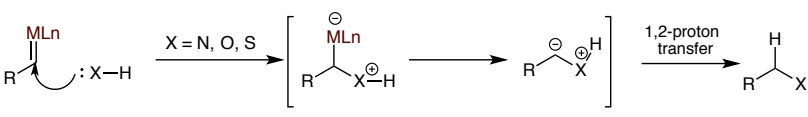

Ylide intermediate

Scheme 11: Transition metal catalysed insertion reactions and mechanisms

In analogy to the diazo derived carbenoids, 36 insertion reaction of sulfoxonium ylide derived carbenoids into polar bonds such as $\mathrm{N}-\mathrm{H}, \mathrm{O}-\mathrm{H}$ and $\mathrm{S}-\mathrm{H}$ will most certainly proceed by a mechanism involving ylide formation and a subsequent 1,2-proton transfer (Scheme 11d). In the case of $\mathrm{C}-\mathrm{H}$ insertion reactions, first metal activates $\mathrm{C}-\mathrm{H}$ bond then ylide will generate metal carbenoid, which undergo migratory insertion into the carbon-metal bond (Scheme 11c).

4.1 $\mathrm{X}-\mathrm{H}(\mathrm{X}=\mathrm{N}, \mathrm{S}, \mathrm{0})$ bond insertions using sulfoxonium ylide derived carbenoids

The first example of a $\mathrm{N}-\mathrm{H}$ insertion using sulfoxonium ylide derived carbenoids was described by Baldwin and co-workers in 1993.12 They demonstrated a formal insertion of one carbon into the $\beta$-lactam for the synthesis of 4-oxopyrrolidinones. First, ring-opening of lactam with methylide $\mathbf{1}$ gave the ketosulfoxonium ylide $\mathbf{5 a}$ in $97 \%$ yield. Treatment of ylide $\mathbf{5 a}$ with $5 \mathrm{~mol} \% \mathrm{Rh}_{2}(\mathrm{TFA})_{4}$ resulted in the $\mathrm{N}-\mathrm{H}$ insertion of an intermediate rhodium carbenoid leading to the desired 4oxopyrrolidinone 29 in $77 \%$ yield (Scheme 12). A range of rhodium catalysts were screened in the reaction affording 4oxoproline scaffolds in $0-77 \%$ yields.
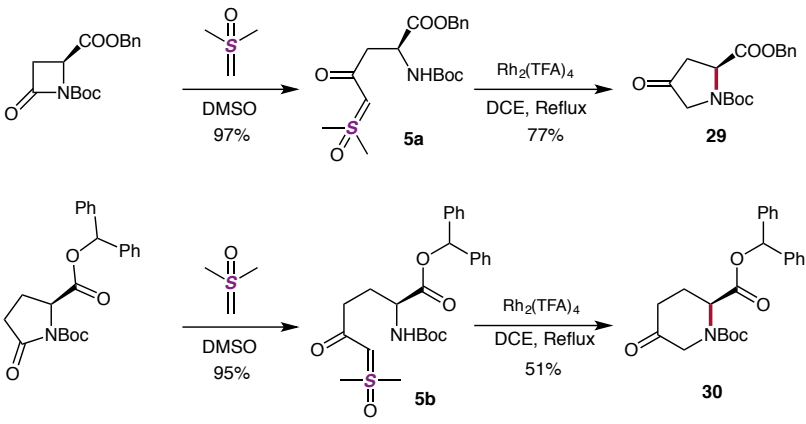

Scheme 12: Sulfoxonium ylide mediated one carbon insertion into lactam bonds

Notably, copper catalysts previously described for generation of sulfonium ylide derived carbenoids by Trost, ${ }^{37}$ Cohen $^{38}$ and Julia $^{39}$ did not afford the $\mathrm{N}-\mathrm{H}$ insertion product. In addition, this 
study was extended to the one carbon homologation of $\gamma$-lactams for the synthesis of 5-oxopipecolic acid $\mathbf{3 0}$ in 51\% yield for the $\mathrm{N}-\mathrm{H}$ insertion step.

In 2009, Mangion's group at Merck investigated a general methodology for the inter- and intramolecular $\mathrm{N}-\mathrm{H}$ insertion of $\alpha$-keto sulfoxonium ylides (Scheme 13). ${ }^{32}$ The reaction of a sulfoxonium ylide $\mathbf{3 1}$ in presence of aniline and $5 \mathrm{~mol} \%$ of rhodium trifluoroacetate led to the $\mathrm{N}-\mathrm{H}$ insertion product in $22 \%$ yield only. The authors stated that the low yield of the reaction is due to deactivation of the catalyst by DMSO. To support this statement, a control reaction was performed by the addition of DMSO prior to the reaction, in which the previous reactivity of sulfoxonium ylide was suppressed. The yields were improved with $[\operatorname{Ir}(\mathrm{COD}) \mathrm{Cl}]_{2}$ as catalyst using degassed dichloromethane or dichloroethane as solvent for $10 \mathrm{~h}$ at room temperature. A range of primary and secondary amines, alcohols and thiols were applied to afford the insertion products in $63-93 \%$ yield (Scheme 13).
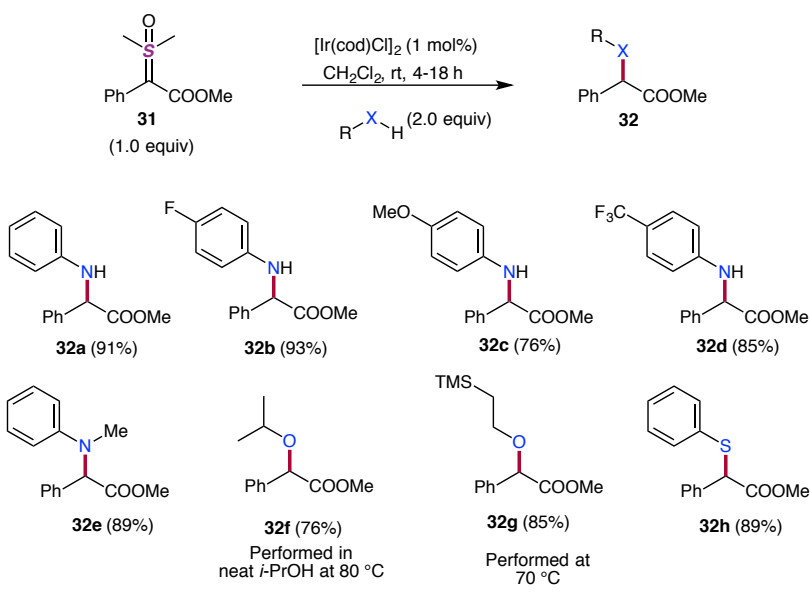

Scheme 13: Ir-catalysed $X-H(X=N, S, O)$ insertion of sulfoxonium ylides

The study was further extended by using other noble metal catalytic systems, such as gold, platinum and silver salts. ${ }^{40}$

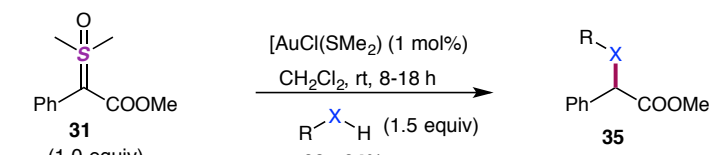

\begin{tabular}{|c|c|c|}
\hline (1.0 equiv) & $60-94 \%$ & \\
\hline \multicolumn{3}{|l|}{$\mathrm{XH}=\mathrm{NH}$} \\
\hline $35 a, R=P h(94 \%)$ & 35b, $\mathrm{R}=p-\mathrm{BrC}_{6} \mathrm{H}_{4}(\mathbf{8 7 \%})$ & $35 c, \mathrm{R}=p-\mathrm{CNC}_{6} \mathrm{H}_{4}(82 \%)$ \\
\hline $35 \mathrm{~d}, \mathrm{R}=p-\mathrm{ClC}_{6} \mathrm{H}_{4}(\mathbf{9 1} \%)$ & $35 \mathrm{e}, \mathrm{R}=p-\mathrm{OMeC}_{6} \mathrm{H}_{4}(\mathbf{8 9} \%)$ & $35 f, R=p-t B_{6} C_{6} H_{4}(\mathbf{8 7} \%)$ \\
\hline
\end{tabular}

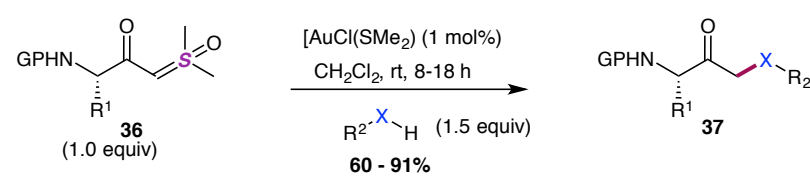$$
\mathrm{XH}=\mathrm{NH}
$$

The reaction yield improved with gold catalysts, especially with $\mathrm{AuCl}\left(\mathrm{SMe}_{2}\right)$, and the reaction of sulfoxonium ylide $\mathbf{3 1}$ with a range of amines and alcohols afforded the insertion products in good yields (60-94\%) (Scheme 14). Moreover, amino acid derived ketosulfoxonium ylides $\mathbf{3 6}$ could also be applied to obtain corresponding $\mathrm{N}-\mathrm{H}$ and $\mathrm{O}-\mathrm{H}$ inserted products 37a-f. Alternative catalysts such as $\mathrm{AuCl}_{3}$ and $\mathrm{Pt}(\mathrm{COD}) \mathrm{Cl}_{2}$ also afforded $\mathrm{N}-\mathrm{H}$ insertion products around $80 \%$ yields. Although there is no direct evidence for gold carbenoid intermediates as these have not sufficient lifetime for NMR observation even at low temperature, the authors proposed that the gold-catalysed reaction followed the same pathway as the iridium-catalysis, rather than via a simple Lewis acid activation.

Moreover, a range of intramolecular N-H insertion reactions of different sulfoxonium ylides related to the prior report by Baldwin $^{12}$ (Scheme 12) were achieved with $[\operatorname{Ir}(\mathrm{COD}) \mathrm{Cl}]_{2}$ in good yields (Scheme 15). 32
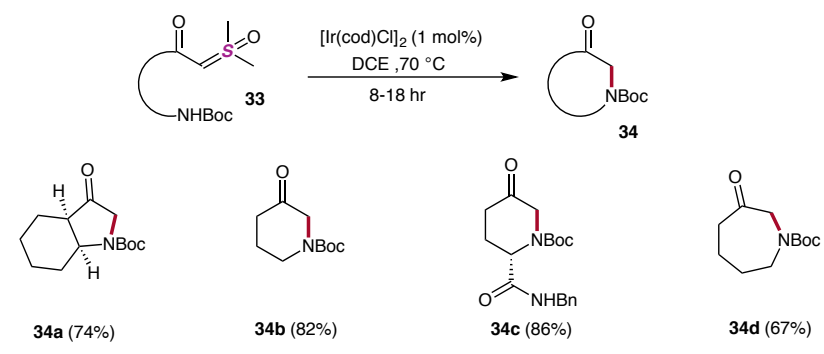

Scheme 15: Ir-catalysed intramolecular $\mathrm{N}-\mathrm{H}$ insertion

In 2011, the first industrial application of the intramolecular N$\mathrm{H}$ insertion of iridium-carbenoid derived from sulfoxonium ylides was shown by Merck (Scheme 16). The synthesis of MK7655 , a $\beta$-lactamase inhibitor could be achieved in 12 steps and $10 \%$ overall yield. ${ }^{41}$ The key transformation of this strategy was the ring expansion of a lactam $\mathbf{3 8}$ using methylide $\mathbf{1}$ to generate a stable sulfoxonium ylide $\mathbf{3 9}$ followed by the iridium-catalysed intramolecular $\mathrm{N}-\mathrm{H}$ insertion to produce chiral 3-piperidinone moiety 40.

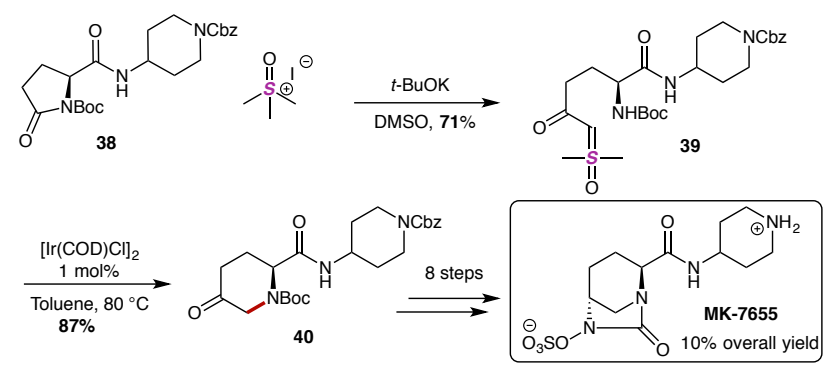

Scheme 16: Ir-catalysed N-H insertion in the synthesis of MK-7655

Furthermore, the process chemists of Merck demonstrated the $\mathrm{N}-\mathrm{H}$ insertion of a metal carbenoid derived from a sulfoxonium ylide at industrial scale in the production of MK-7246, a selective CRTH2 antagonist with potential in the treatment of respiratory disease (Scheme 17). ${ }^{42}$ The key step of this approach was a $[\mathrm{IrCl}(\mathrm{cod})]_{2}$-catalysed intramolecular indole $\mathrm{N}-\mathrm{H}$ insertion reaction which afforded $\mathbf{4 2}$ in $83 \%$ yield. The eight-step synthesis requires no chromatographic purification and was scaled up to more than $100 \mathrm{~kg}$ in a pilot plant. 

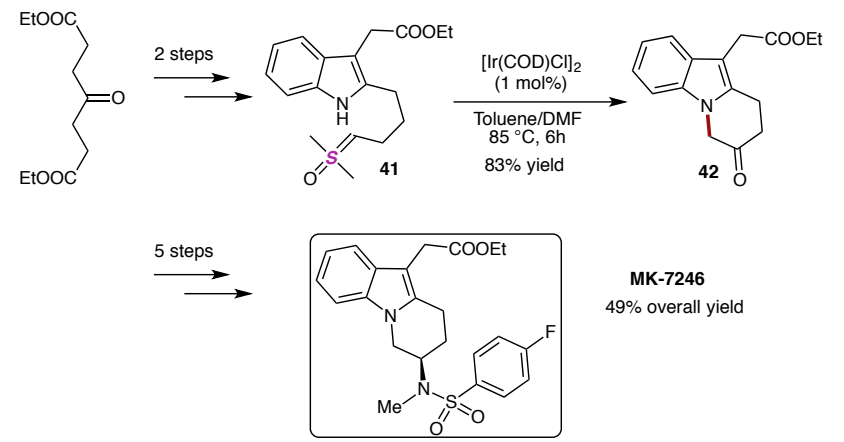

Scheme 17: Ir-catalysed N-H insertion in the synthesis of MK-7246

In 2016, the group of Schomaker and Shekhar studied the iridium-catalysed $\mathrm{N}-\mathrm{H}$ insertion of sulfoxonium ylides for the synthesis of imidazo-fused pyrrolopyrazines $\mathbf{4 6}$ (Scheme 18). ${ }^{43}$ The authors found that the reaction outcome was greatly controlled by the addition of a bidentate $\mathrm{N}, \mathrm{N}$-ligand. When $[\mathrm{Ir}(\mathrm{COD}) \mathrm{Cl}]_{2}$ was employed as catalyst without ligand, $\mathrm{N}-\mathrm{H}$ insertion of $\mathbf{4 4}$ afforded the $\beta$-keto amine 45. Addition of 1,10phenantroline as a ligand and NaOTf to generate a cationic iridium catalyst gave imidazo-fused pyrrolopyrazines $\mathbf{4 6}$ as major product. NMR studies indicated that in the absence of ligand the 2-aminopyridine reactant $\mathbf{4 4}$ is coordinating the iridium catalyst. Kinetic studies showed that generation of the iridium carbenoid was reversible and rate-limiting step.

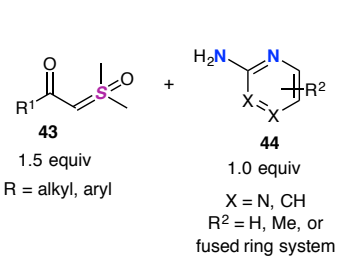

Method A: $[\mathrm{Ir}(\mathrm{COD}) \mathrm{Cl}]_{2}(2.5 \mathrm{~mol} \%)$

Method $\mathrm{A} .\left(\mathrm{Ir}(\mathrm{COD}) \mathrm{Cl}_{2}(2.5 \mathrm{~mol})\right.$

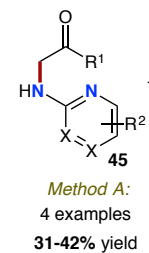

4 examples
$\mathbf{3 1 - 4 2} \%$ yield

Ratio of $45 / 46=4 / 1$ to $40 / 1$ Method B: $\left[\mathrm{Ir}(\mathrm{COD}) \mathrm{Cl}_{2}(2.5 \mathrm{~mol} \%)\right.$ $1,10-$ phenanthroline $(5 \mathrm{~mol} \%)$
NaOTf $(5 \mathrm{~mol} \%)$
Scheme 18: Influence of ligand on Ir-catalysed $\mathrm{N}-\mathrm{H}$ insertion of sulfoxonium ylides

Recently, the group of Hopmann reported the preparation of indoles utilizing sulfoxonium ylide derived iridium carbenoids (Scheme 19).33 Commercially available unprotected anilines directly converted to indoles $\mathbf{4 7}$ in one step, while previously reported procedures required either $\mathrm{N}$-substitution on the aniline ring (e.g., aryl hydrazones, imines, enamines, acetanilides) or ortho functionalized anilines (e.g. $o$-halo, $o$-vinyl, $o$-acyl, $o$-alkynyl, $o$-halomethyl anilines). A range of sulfoxonium ylides underwent smooth cyclization in the presence of $[\mathrm{IrCl}(\operatorname{cod})]_{2}$ and a Bronsted acid, resulting in the formation of corresponding indoles in moderate to good yields. Further, this method demonstrated the stability of $\alpha$-ketosulfoxonium ylides under high reaction temperatures compared to $\alpha$-diazo compounds, which may undergo either decomposition or Wolf rearrangement. Control studies revealed that $\mathrm{N}-\mathrm{H}$ insertion occurred only in the presence of iridium catalyst and the subsequent cascade of imine formation, substitution and aromatization was catalysed by the Bronsted acid (Scheme 20).
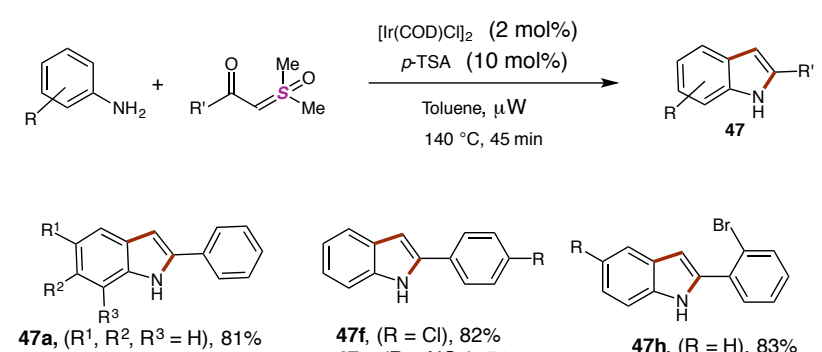

$\begin{array}{ll}\text { 47a, }\left(R^{1}, R^{2}, R^{3}=H\right), 81 \% & \mathbf{4 7 f},(R=C l), 82 \% \\ \text { 47b, }\left(R^{1}=M e, R^{2}, R^{3}=H\right), 85 \% & 47 g,\left(R=N_{2}\right), 54 \%\end{array}$ $47 c,\left(R^{1}=O M e, R^{2}, R^{3}=H\right), 69 \%$ 47d, $\left(R^{1}=S M e, R^{2}, R^{3}=H\right), 62 \%$ 47e, $\left(R^{1}=H, R^{2}, R^{3}=M e\right), 71 \%$
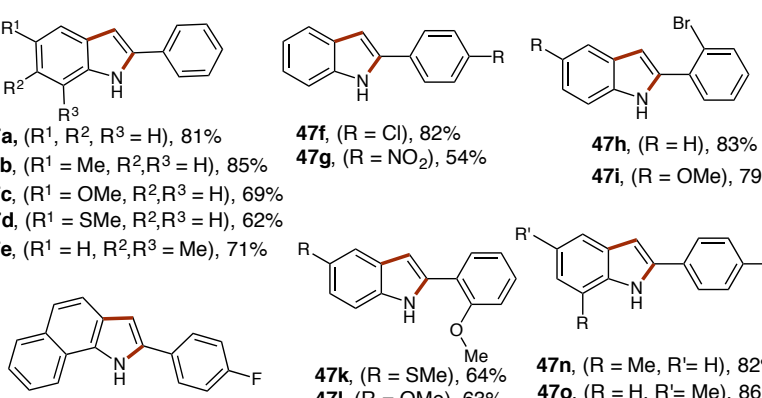

47h, $(R=H), 83 \%$ $47 \mathrm{i},(\mathrm{R}=\mathrm{OMe}), 79 \%$

47k, $(R=S M e), 64 \% \quad 47 n,\left(R=M e, R^{\prime}=H\right), 82 \%$ 47I, $(R=O M e), 63 \% \quad 470,\left(R=H, R^{\prime}=M e\right), 86 \%$ 47j, $(72 \%)$ $47 \mathrm{~m},(\mathrm{R}=\mathrm{Me}), 76 \%$

Scheme 19: Ir-catalysed N-H insertion for the synthesis of indoles

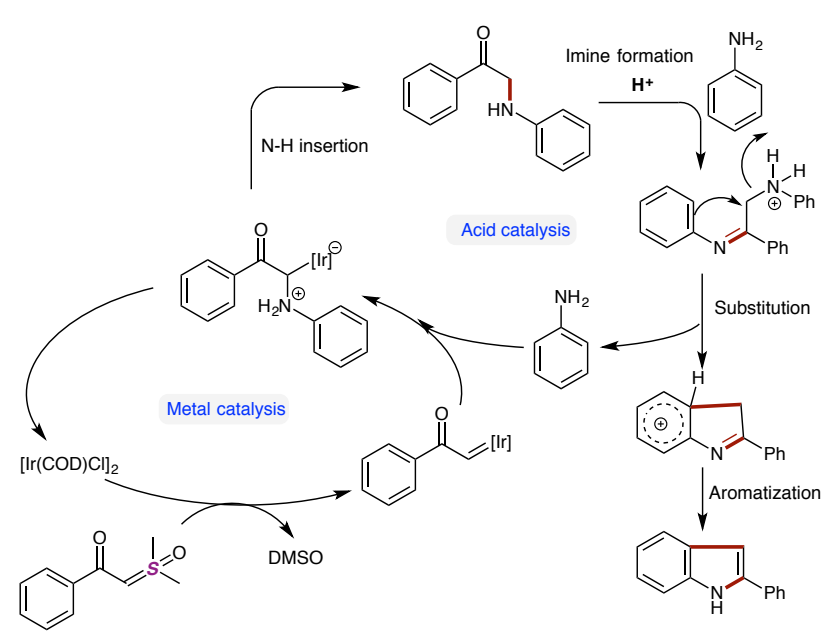

Scheme 20: Proposed mechanism for Ir-catalysed synthesis of indoles

\section{2 $\mathrm{C}-\mathrm{H}$ functionalization using sulfoxonium ylides}

Transition metal-catalysed $\mathrm{C}-\mathrm{H}$ functionalization has been progressively explored as an efficient approach for the construction of $\mathrm{C}-\mathrm{C}$ bonds. Although the $\mathrm{C}-\mathrm{H}$ insertion of diazo derived carbenoids has been extensively described, only very few examples of $\mathrm{C}-\mathrm{H}$ insertion reactions employing sulfoxonium ylide derived carbenoids have been published. ${ }^{4}$ Initially, the group of Mangion attempted a $\mathrm{C}-\mathrm{H}$ functionalization using sulfoxonium ylide derived iridium carbenoids and observed homo coupling of ylide instead of $\mathrm{C}-\mathrm{H}$ insertion (Scheme 10). ${ }^{32}$ The authors reasoned that sulfoxonium ylides are more nucleophilic than diazo compounds and consequently the ylides can attack the generated carbenoids leading to dimerization instead of $\mathrm{C}-\mathrm{H}$ insertion.

In 2017, the group of Hopmann reported the first example of a $\mathrm{C}-\mathrm{H}$ functionalization using sulfoxonium ylide derived carbenoids. $^{33}$ In addition to N-H insertion (Scheme 19), the authors investigated the metal- and acid-catalysed $\mathrm{C}-\mathrm{H}$ insertion of stabilized enamines with sulfoxonium ylides and obtained a range of substituted pyrroles 49 (Scheme 21). The versatility of the method was demonstrated by the synthesis of the pyrrole subunit $49 \mathrm{~m}$ of atorvastatin (Lipitor), a cholesterol-lowering drug. This approach is also viable for a one pot three component synthesis of pyrroles using in situ generated 
$\beta$-enaminoester 48 (from amines and $\beta$-ketoesters) with sulfoxonium ylide derived carbenoids

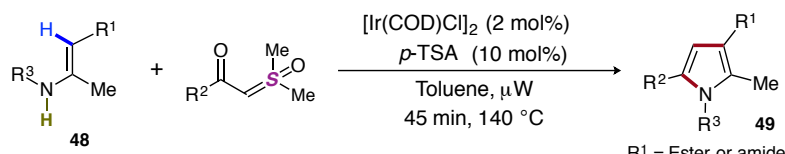

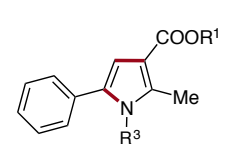

49a, $\left(R^{1}=M e, R^{3}=B n\right), 78 \%$ 49b, $\left(R^{1}=M e, R^{3}=P M B\right), 75 \%$

49d, $\left(R^{1}=E t, R^{3}=H\right), 64 \%$

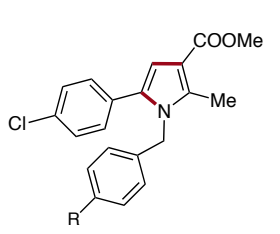

49i, $(\mathrm{R}=\mathrm{Ph}), 66 \%$ $49 \mathrm{j},(\mathrm{R}=\mathrm{OMe}), 64 \%$ 49c, $\left(R^{1}=M e, R^{3}=C y\right), 69 \%$

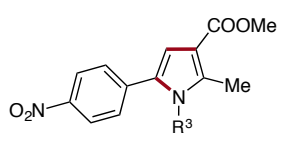

49e, $\left(R^{3}=C y\right), 78 \%$ $49 f,\left(R^{3}=B n\right), 60 \%$

49g, $\left(R^{4}=O M e, R^{5}=H\right), 62 \%$

$49 h,\left(R^{4}=H, R^{5}=F\right), 69 \%$
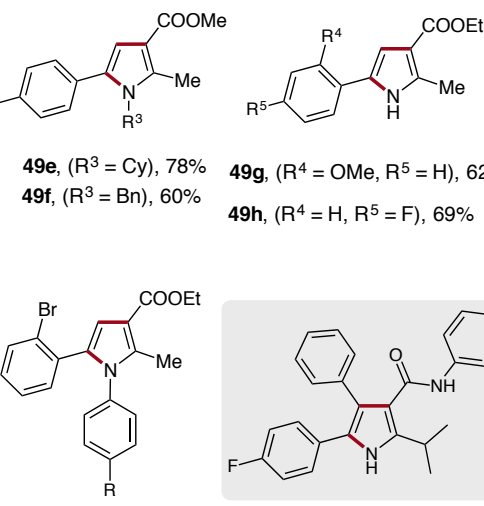

$49 k,(R=H), 57 \%$

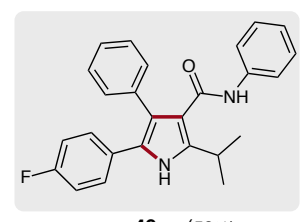

$49 \mathrm{~m},(58 \%)$

$49 \mathrm{l},(\mathrm{R}=\mathrm{OMe}), 55 \%$
Scheme 21: Ir-catalysed $\mathrm{N}-\mathrm{H}$ insertion for the synthesis of pyrroles

Notably, the iridium carbenoids derived from sulfoxonium ylides selectively underwent $\mathrm{C}-\mathrm{H}$ insertion rather than $\mathrm{N}-\mathrm{H}$ insertion of $\beta$-enaminoesters (Scheme 22), while diazo derived carbenoids are known to undergo both $\mathrm{C}-\mathrm{H}$ and $\mathrm{N}-\mathrm{H}$ insertions. ${ }^{45}$ The authors proposed the mechanism shown in Scheme 22. The $\mathrm{C}-\mathrm{H}$ insertion of carbenoid plausibly proceeds by a stepwise mechanism (Scheme 11D) due to the highly nucleophilc $\beta$-carbon of the $\beta$-enaminoesters $\mathbf{4 8}$.

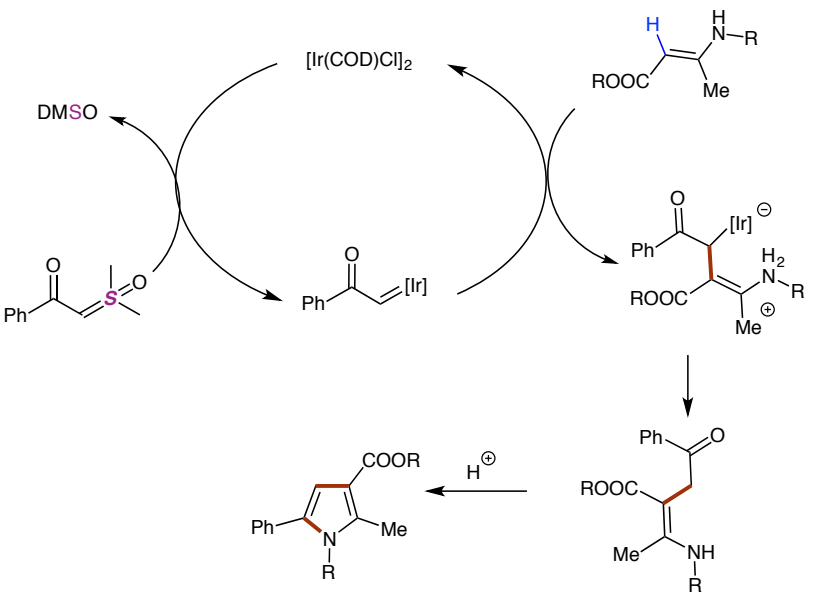

Scheme 22: Proposed mechanism for Ir-catalysed synthesis of pyrroles.

In 2017, the groups of Aïssa and Li simultaneously reported the rhodium-catalysed activation of $\mathrm{C}\left(\mathrm{sp}^{2}\right)-\mathrm{H}$ bonds of arenes with sulfoxonium ylides. The group of Aïssa used various directing groups to study the $\mathrm{C}-\mathrm{H}$ acylmethlyation of arenes and heteroarenes with sulfoxonium ylide derived rhodium carbenoids (Scheme 23). ${ }^{46}$ Methyl substitution at the ylide carbon $\left(\mathrm{R}^{2}=\mathrm{Me}\right)$ was also successful for this $\mathrm{C}-\mathrm{H}$ insertion reaction to yield 50f, albeit with lower yield. The authors utilized this strategy for the synthesis of 2-substituted indole $\mathbf{5 1}$ and $\mathrm{N}$-methoxylactam $\mathbf{5 2}$ by directing group induced $\mathrm{C}-\mathrm{H}$ activation of arene followed by removal of directing group (Scheme 23B).

\section{A. Scope for C-H insertion}

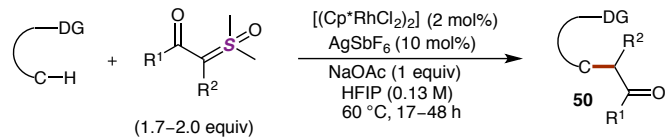<smiles>O=C(Cc1ccccc1)c1ccccc1-c1ccccc1</smiles>

$50 \mathrm{a},(92 \%)$<smiles>CC(C)C(=O)Cc1cccn1-c1ccccn1</smiles>

50d, (75\%)<smiles>O=C(Cc1ccccc1-c1ccccn1)c1ccco1</smiles>

50b, $(97 \%)$<smiles>O=C(Cc1occc1-c1ccccn1)[C@H]1C[C@@H]1c1ccccc1</smiles>

$50 e,(63 \%)$

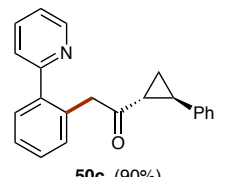

50c, $(90 \%)$
B. Applications of $\mathrm{C}-\mathrm{H}$ inserted products
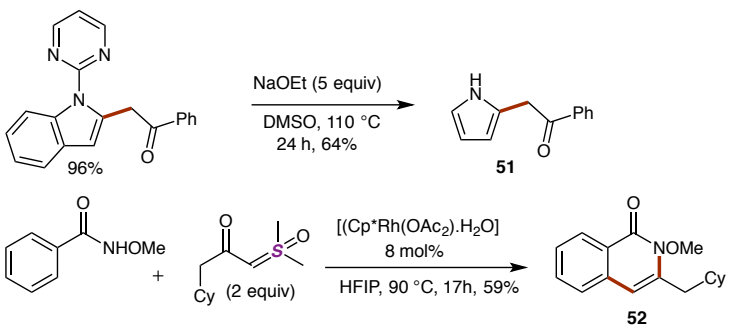

Scheme 23: $\mathrm{C}-\mathrm{H}$ insertion of arenes using sulfoxonium ylide derived carbenoids and its applications

The reaction proceeded by a sequence of $\mathrm{C}-\mathrm{H}$ activation of arene, migratory insertion of the ylide into the carbon-metal bond, and protodemetalation (Scheme 24). The authors have given strong evidence of ylide migratory insertion complex $\mathbf{5 4}$ by X-ray crystallographic confirmation. Moreover, mechanistic exploration for this result suggested that the metal insertion of arene $\mathrm{C}-\mathrm{H}$ is not only reversible but also faster than the overall reaction and protodemetalation is the rate-limiting step.

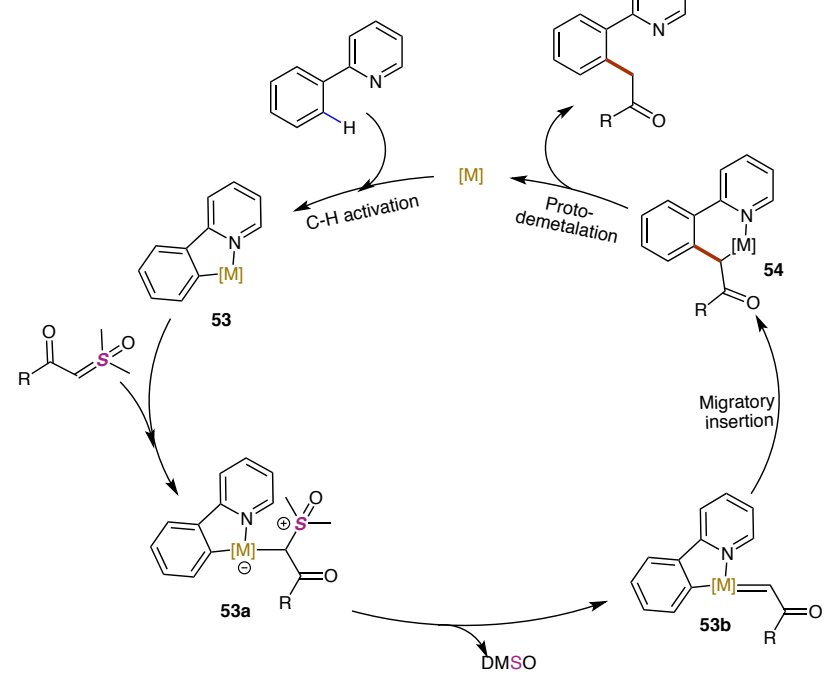

Scheme 24: Proposed mechanism for $\mathrm{C}-\mathrm{H}$ activation of arenes followed by insertion of sulfoxonium ylide derived carbenoids

Li's group showed different examples of directing group assisted $\mathrm{C}-\mathrm{H}$ acylmethlyation of arenes using sulfoxonium ylides in the presence of Rh(III) catalysts (Scheme 25). ${ }^{47}$ In this method, addition of $\mathrm{Zn}(\mathrm{OAc})_{2}$ ( 0.6 equiv) and $\mathrm{PivOH}$ (2 equiv) was 
necessary to obtain good yields. The authors utilized a natural product-derived sulfoxonium ylide to generate the complex molecular framework 55b in 34\% yield and demonstrated the gram scale synthesis of 2-vinyl indole. The authors observed both mono alkylated product $\mathbf{5 5} \mathbf{f}$ and dialkylated product $\mathbf{5 5} \mathrm{g}$ for the $\mathrm{C}-\mathrm{H}$ acylmethlyation of 1-phenylpyrazole.<smiles>CC(=O)C=[SH](C)(C)C1(C)CC1</smiles>

55 a $(96 \%)$
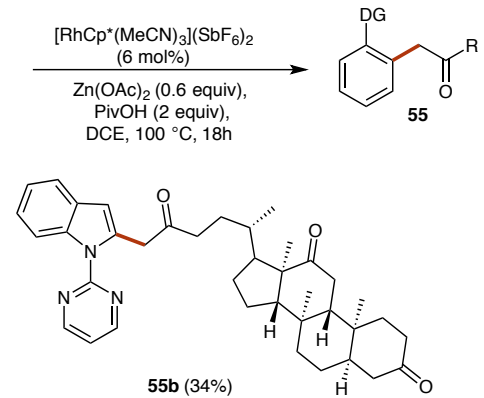

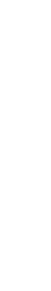

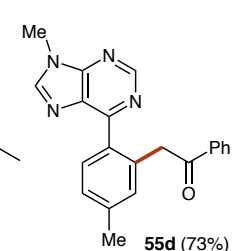<smiles>CC(C)(C)[13C](=O)c1cccc(N2CCc3cccc(CC(=O)c4ccccc4)c32)n1</smiles>

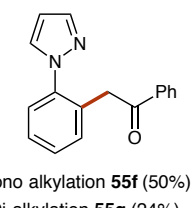

$\mathbf{5 5 e}(45 \%) \quad$ Di alkylation $\mathbf{5 5 g}(24 \%)$

Scheme 25: C-H acylmethylation of arenes using sulfoxonium ylide derived carbenoids

Prior to this report (Scheme 25), Li's group demonstrated direct synthesis of 1-naphthols from Rh(III)-catalysed annulation of sulfoxonium ylides with alkynes under redox neutral conditions (Scheme 26). ${ }^{48}$ In this reaction, the sulfoxonium group of the ylide function as both activating group as well as eliminating group. A wide range of 1-napthols were obtained with diverse sulfoxonium ylides and internal alkynes. This reaction was successful with symmetrical diphenyl acetylene $\mathbf{5 6}$ a-d and unsymmetrical 1,2-alkyl-aryl alkynes 56e-g with excellent regioselectivity. However, 1,2-dialkyl alkynes failed to afford 1napthols. The authors further demonstrated the utility of this method by gram-scale synthesis of 1-naphthols and their triflate derivatives 57, which are important reactants for transition metal-catalysed cross coupling reactions.

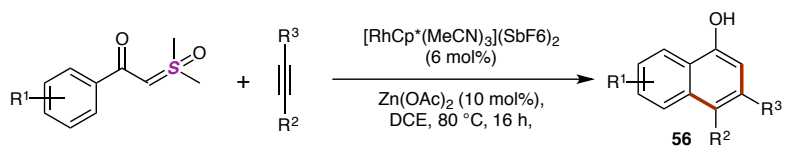

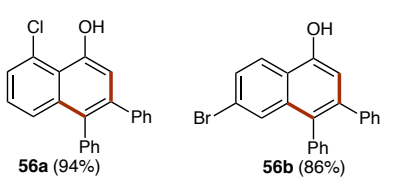<smiles>O=[N+]([O-])c1ccc2c(O)cc(O)c(-c3ccccc3)c2c1</smiles><smiles>Oc1cc(I)c([18OH])c2ccsc12</smiles>

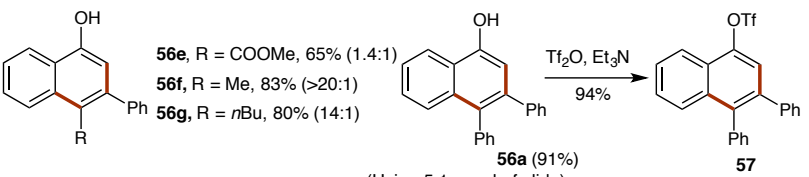

(Using $5.1 \mathrm{mmol}$ of ylide)

Scheme 26: $\mathrm{Rh}$ (III)-catalysed synthesis of naphthols via $\mathrm{C}-\mathrm{H}$ activation of sulfoxonium ylides

A plausible mechanism for this reaction is shown in Scheme 27. Initially, coordination of the rhodium catalyst to the oxygen of the ylide followed by cyclometallation deliver a five-membered rhodacyclic intermediate 58a. Then, coordination of alkyne to the rhodacycle followed by migratory insertion of the aryl group into alkyne afford a seven-membered intermediate 58c. Subsequent elimination of DMSO lead to $\alpha$-oxo carbenoid intermediate $\mathbf{5 8 d}$ which under protonolysis afford 1-naphthol.

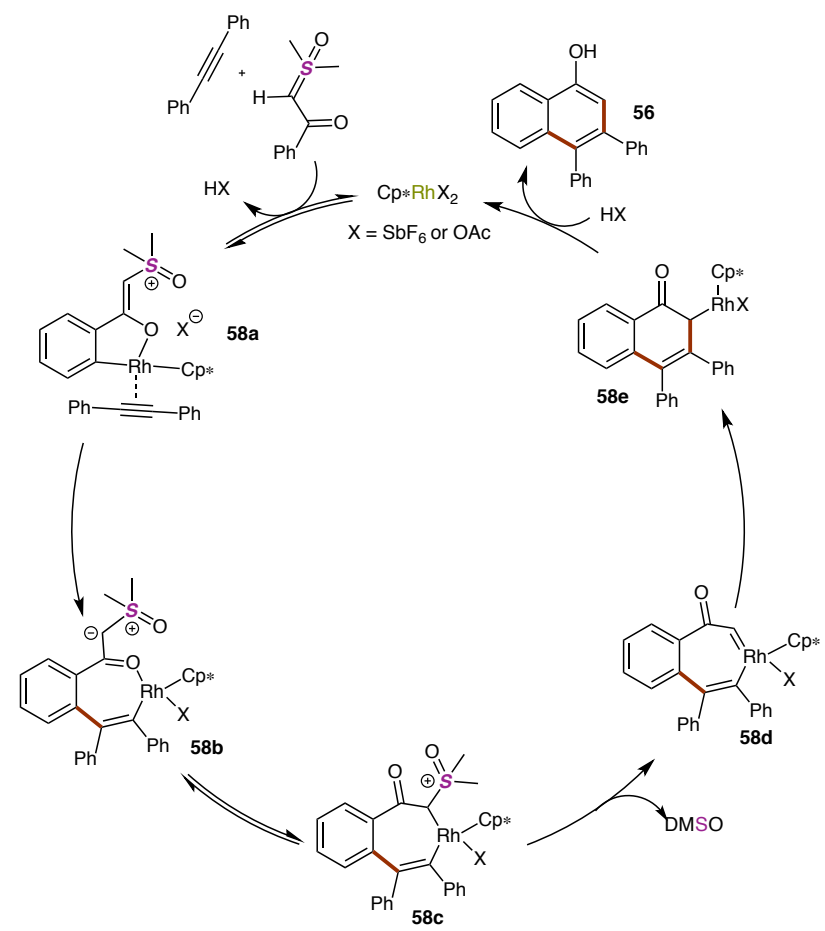

Scheme 27: Proposed reaction mechanism for synthesis of naphthols

In early 2018, Li's group reported a general strategy to synthesize structurally diverse hetero- and carbocycles via $\mathrm{Rh}-$ catalysed annulative coupling between arenes and sulfoxonium ylides (Scheme 28).49 In this strategy, reaction of sulfoxonium ylide derived rhodium carbenoids with sulfoximines $59(X=S)$ leads to 1,2-benzothiazine adduct $\mathbf{6 0}(\mathrm{X}=\mathrm{S})$. The coupling of commercially available enantiopure sufoximines $\mathbf{6 1}$ afforded corresponding 1,2-benzothiazine adducts $\mathbf{6 2}$ without the erosion of the enantiopurity. Reaction of benzophenone $\mathrm{NH}$ imines $59(\mathrm{X}=\mathrm{C})$ with sulfoxonium ylides under rhodiumcatalysed conditions gave 2-amino isoquinolines 60c $(\mathrm{X}=\mathrm{C})$, which can be used as a precursor for another $\mathrm{C}-\mathrm{H}$ functionalization. The reaction is also successful with ketoximes 63 and yielded isoquinoline $\mathrm{N}$-oxides 64 with good yields. Analogously, the reaction of sulfoxonium ylide with 2phenylimidazo[1,2-a]pyridines $\mathbf{6 5}$ afforded corresponding carbo-annulated products 66 in high yields. On the basis of mechanistic investigations, the authors proposed that hetero annulation proceeds via intermediate $\mathbf{6 7}$ and carboannulation proceeds via intermediate $6 \mathbf{8}$. 


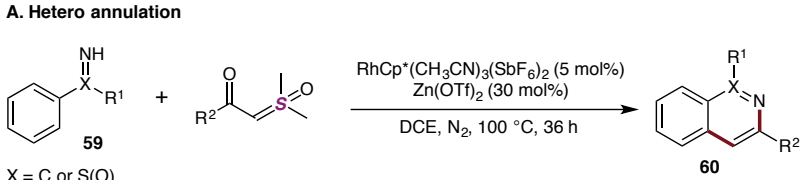

$\mathrm{X}=\mathrm{C}$ or $\mathrm{S}(\mathrm{O})$<smiles>O=S1(=O)N=C2C(=CC(c3ccccc3)=N[SH]2(=O)c2ccccc2)c2ccccc21</smiles><smiles></smiles><smiles>c1ccc(Nc2nc(-c3ccccc3)cc3ccccc23)cc1</smiles><smiles>CCCCCC(C)(C)C</smiles>

$60 a(86 \%)$ $60 \mathrm{~b}(82 \%)$

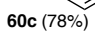
60d $(54 \%)$

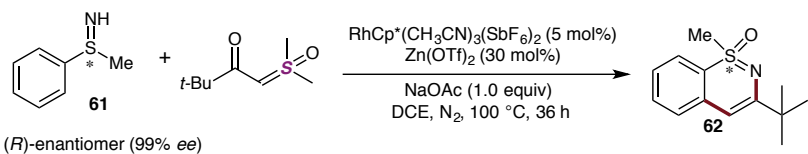

(R)-enantiomer ( $99 \%$ ee)

(S)-enantiomer $(99 \%$ ee)

(R)-62, 89\% yield and $99 \%$ ee (S)-62, 92\% yield and $99 \%$ ee<smiles>C/C(=N\O)c1ccccc1</smiles>

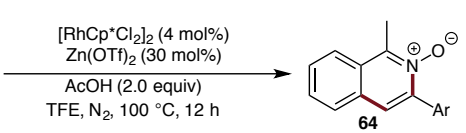

B. Carbo annulation

$$
\begin{gathered}
60-87 \% \\
16 \text { examples }
\end{gathered}
$$
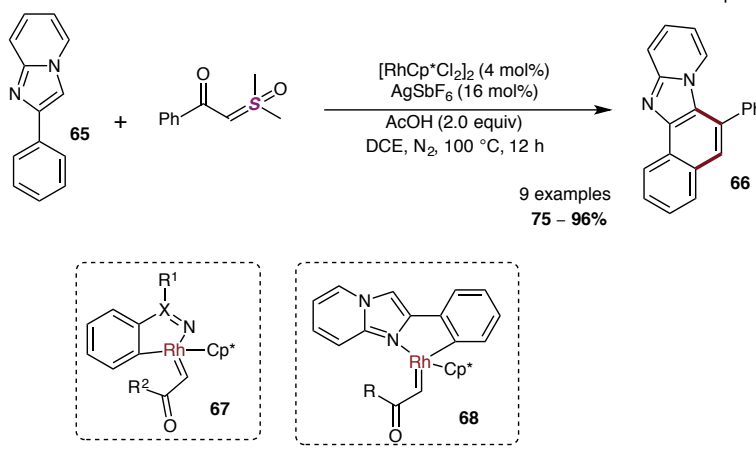

Scheme 28: Rh-catalysed annulative coupling between arenes and sulfoxonium ylides

Very shortly after Li's publication, ${ }^{49}$ Cheng's group independently reported a similar rhodium-catalysed ortho $\mathrm{C}-\mathrm{H}$ activation and cyclization sequence between $\alpha$-aroyl sulfoxonium ylides and 2-arylimidazoles 65, leading to imidazo[2,1-a]isoquinolines scaffolds 66 (Scheme 29).50 Substituents at the ortho-position of the aryl group did not impede the reaction (66f, $75 \%$ ). Notably, in the case of metasubstituted 65, the cyclization preferred to take place at the least hindered ortho-position and only regioisomer $66 \mathrm{~g}$ was observed. The reaction was successful in the presence of air.
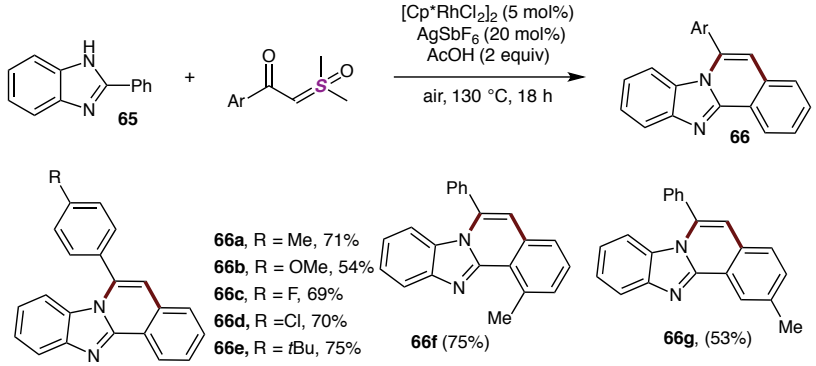

Scheme 29: Rh-catalysed annulative coupling between 2-arylimidazoles and sulfoxonium ylides

At the same time, Zeng's group also reported a synthesis of 1,2benzothiazines via ruthenium-catalysed sequential aryl $\mathrm{CH}$ activation/cyclization of S-arylsulfoximines with sulfoxonium ylides (Scheme 30). ${ }^{51}$ Electron-deficient sulfur ylides more easily formed a ruthenium-carbenoid, which cyclized with sulfoximine to afford 1,2-benzothiazine $\mathbf{7 0 e}$ in better conversion. However, electron-deficient S-phenylsulfoximines including S-(4nitrophenyl)sulfoximine $\quad\left(69-\mathrm{NO}_{2}\right) \quad$ and $\mathrm{S}-(4-$ acetylphenyl)sulfoximine (69-acyl), did not afford the corresponding 1,2-benzothiazines. S-(2- pyridyl)sulfoximine (69-Py) did not tolerate the reaction system possibly due to that $\mathrm{Ru}(\mathrm{II})$ salts coordinated with pyridine "N" lost their catalytic activity. Moreover, the afforded 1,2-benzothiazines in this method could be converted into various 4-substituted 1,2benzothiazine analogues for versatile synthetic applications.
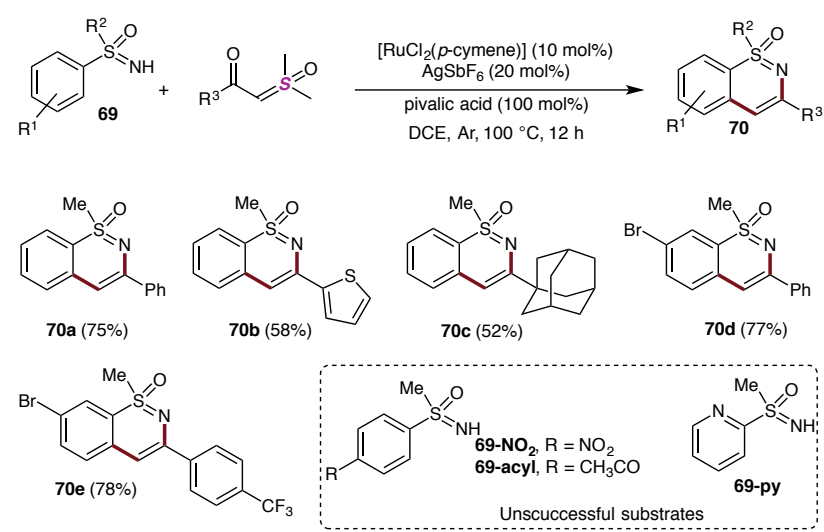

Scheme 30: Ru-catalysed annulative coupling between sulfoximines and sulfoxonium ylides

The proposed mechanism of the reaction (Scheme 31) is similar to the rhodacycle mechanism (Scheme 24). Coordination of the active $\mathrm{Ru}(\mathrm{II})$ catalyst to the nitrogen of sulfoximine $\mathbf{6 9}$ followed by $\mathrm{C}\left(\mathrm{sp}^{2}\right)-\mathrm{H}$ activation via electrophilic ruthenation generates a five-membered ruthenacycle 71a. Then, nucleophilic attack of sulfoxonium ylide on the ruthenacycle produce a ruthenium(II) carbenoid $\mathbf{7 1 b}$, which further undergoes carbenoid migratory insertion to generate the six-membered ruthenacycle $\mathbf{7 1 c}$. Finally, protonolysis with release of the Ru(II) catalyst followed by the intramolecular condensation of the imine and the carbonyl group produces 1,2-benzothiazine $\mathbf{7 0}$.

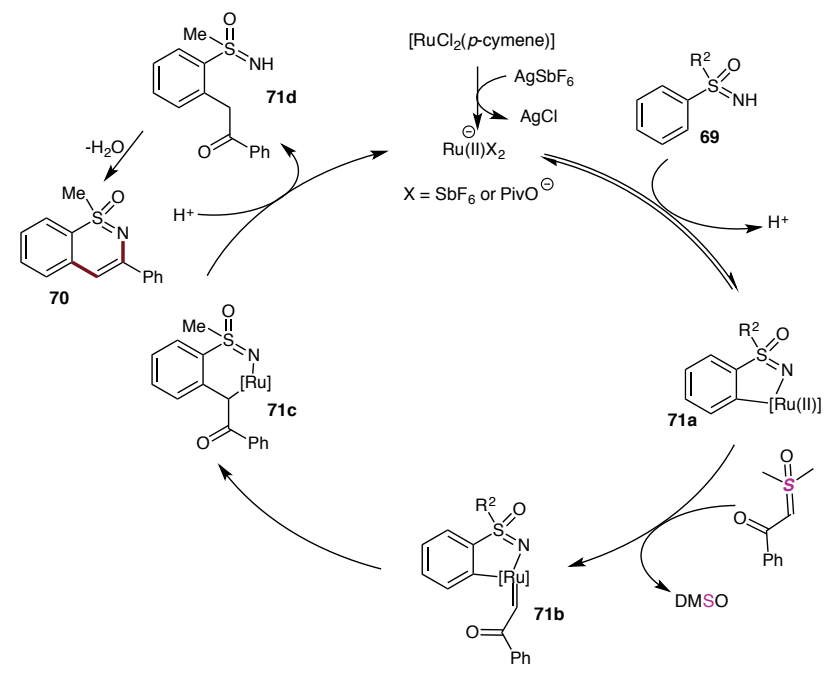

Scheme 31: Proposed mechanism for Ru-catalysed annulative coupling between sulfoximines and sulfoxonium ylides 
In 2018, Fan's group developed a highly chemo- and regioselective synthesis of benzo[a]carbazoles $\mathbf{7 3 a - c}$ and indolo[2,1-a]isoquinolines 73d through coupling of 2-aryl indoles with sulfoxonium ylide derived Rh(III)-carbenoids (Scheme 32). ${ }^{52}$ By strategically placing substituents with suitable reactivity at the 3-position of indoles $\mathbf{7 2 a - d}$ - diverse heterocyclic products were obtained. 3-unsubstituted indole 72a provided benzo $[a]$ carbazoles $\mathbf{7 3 a}$, while formyl or cyano groups at $\mathrm{C}_{3}$ afforded 5-acylbenzo $[a]$ carbazoles $\mathbf{7 3 b}$ and 6-amino-5acylbenzo $[a]$ carbazoles $73 \mathrm{c}$ respectively. This method was also applied for largescale synthesis (5 mmol scale) of benzo[a]carbazoles and afforded $\mathbf{7 6}$ in $68 \%$ yield. Mechanistically, all transformations were suggested to proceed via a common intermediate $\mathbf{7 5 b}$ obtained from a sequence of coordination/C-H activation, carbenoid formation and insertion (similar to the sequence shown in Scheme 24). The resulting intermediate products $\mathbf{7 4 a - d}$ transformed through different condensation pathways determined by the $C_{3}$ substituent providing $\mathbf{7 3 a - d}$.

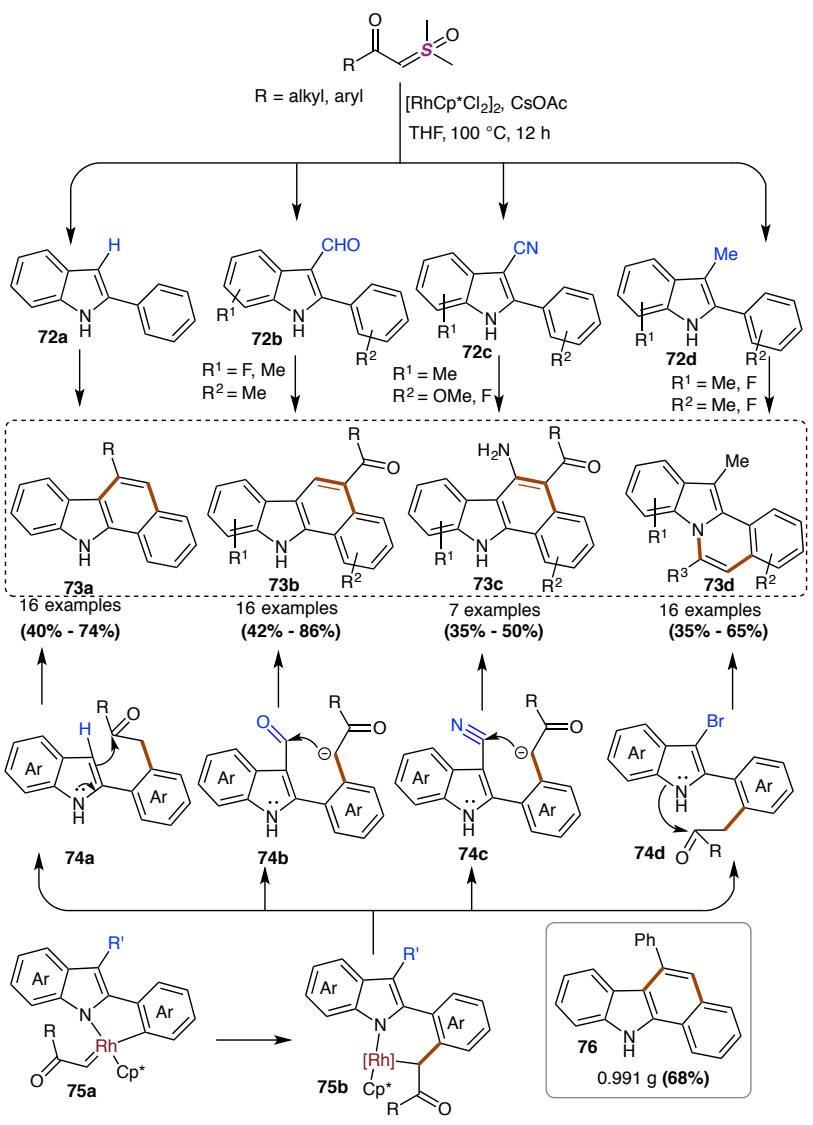

Scheme 32: Rh(III)-catalysed C-H functionalization and annulations of 2arylindoles with sulfoxonium ylides

In 2018, Ellman's group developed a unique imidoyl C-H activation for the synthesis of azolopyrimidines $\mathbf{7 8}$ by coupling of azoloaldimines $\mathbf{7 7}$ with sulfoxonium ylide derived carbenoids (Scheme 33). ${ }^{53}$ The imidoyl C-H activation was confirmed by Xray crystallographic characterization of rhodacycle 79. Further mechanistic investigation revealed that the imidoyl $\mathrm{C}-\mathrm{H}$ activation step is slightly reversible and rate-limiting. This reaction was also investigated using alkynes and diazo compounds in place of sulfoxonium ylides providing azolopyrimidines in good yields.

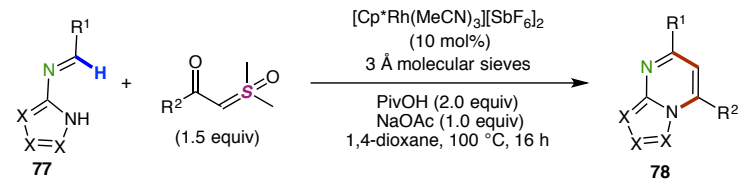<smiles>Cc1cccc(-c2cc(-c3ccccc3)nc3nccn23)c1</smiles><smiles>O=[N+]([O-])c1cccc(-c2cc(-c3ccco3)nc3nccn23)c1</smiles><smiles>Cc1cccc(-c2cc(-c3ccccc3)nc3c4ccccc4nn23)c1</smiles><smiles>CCCc1cc(-c2ccccc2)nc2nccn12</smiles><smiles>c1ccc(-c2cc(-c3cccs3)n3ccnc3n2)cc1</smiles><smiles>Fc1ccc(-c2cc(-c3ccccc3)nc3c(-c4ccccc4)cnn23)cc1</smiles>

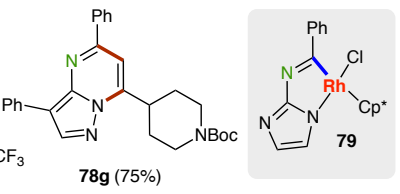

Scheme 33: Rh(III) catalysed imidoyl C-H activation and annulation to azolopyrimidines

Ellman et al. extended their study to activate alkenyl C-H for the synthesis of other $\mathrm{N}$-fused [5,6]-bicyclic heterocycles (Scheme 34). ${ }^{54}$ In this study, 2-alkenyl imidazoles and triazoles 80 reacted with sulfoxonium ylide derived rhodium carbenoids via rhodacycle 82 to annulated heterocycles $\mathbf{8 1}$. Remarkably, the reaction was carried out at bench-top conditions at $2 \mathrm{mmol}$ scale for aryl and alkyl sulfoxonium ylides without dry reaction conditions.
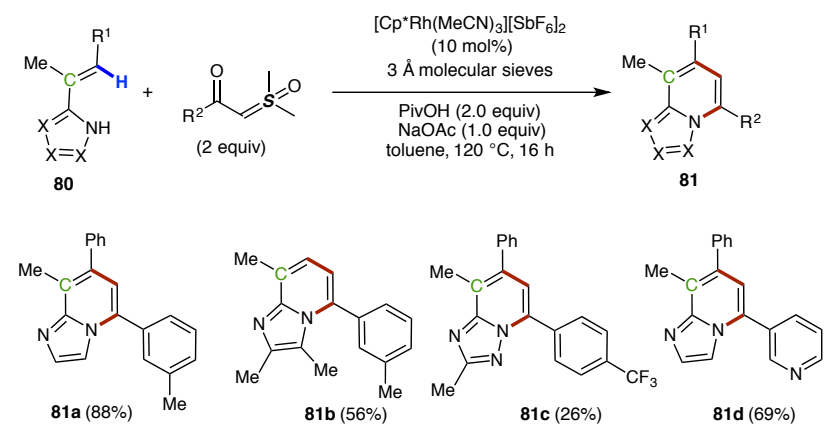<smiles>[X]c1c(-c2ccccc2)cc(-c2ccccc2)n2ccnc12</smiles><smiles>Cc1c(-c2ccccc2)cc(C(N)O[Na])n2ccnc12</smiles>

81e, $X=O, 59 \%$
$81 f, X=S, 68 \%$

$\mathbf{8 1 g},(58 \%, 3: 1 \mathrm{er})$<smiles>Cc1cc(C2CC[Nb+]([O-])CC2)n2ccnc2c1[N+](=O)[O-]</smiles>

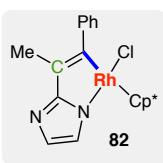

Scheme 34: $\mathrm{Rh}$ (III) catalysed imidoyl C-H activation of C-alkenyl azoles

In 2018, the groups of Kim and Cheng independently developed a method for intramolecular annulation reactions between azobenzenes $\mathbf{8 3}$ and sulfoxonium ylide derived rhodium carbenoids producing highly substituted indazoles $\mathbf{8 4}$ (Scheme 35). ${ }^{55}$ In this report azobenzenes can function as an electrophilic directing group, while aforementioned reports used nucleophilic directing groups for $\mathrm{C}-\mathrm{H}$ activation and annulation sequence. A wide range of symmetrical azobenzenes successfully afforded indazoles, however, sterically congested disubstituted azobenzene did not provide the corresponding indazole 84c. In the case unsymmetrical azobenzenes, the reactions predominantly occurred at the $\mathrm{C}-\mathrm{H}$ bonds of the electron-rich aromatic ring to provide the regioisomer $\mathbf{8 4}$ ga as major product. 
${ }^{\mathrm{R}} \mathrm{X}$<smiles>C1=CCC(N=Nc2ccccc2)=C1</smiles>

$$
\begin{aligned}
& \begin{array}{l}
\backslash_{\text {II }} \\
\left.\mathrm{RhCp}^{*} \mathrm{Cl}_{2}\right]_{2}(2.5 \mathrm{~mol} \%) \\
\mathrm{AgSbF}_{6}(10 \mathrm{~mol} \%)
\end{array} \\
& \underset{A r}{=0} \begin{array}{c}
\frac{\mathrm{Cu}(\mathrm{OAc})_{2}(50 \mathrm{~mol} \%)}{\mathrm{CuCO}_{3} \cdot \mathrm{Cu}(\mathrm{OH})_{2}(100 \mathrm{~mol} \%)} \\
\mathrm{DCE}, 110^{\circ} \mathrm{C}, 24 \mathrm{~h}
\end{array}
\end{aligned}
$$

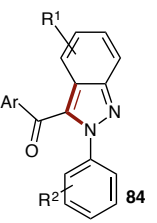<smiles>CCc1ccc2nn(-c3ccc([14CH3])cc3)c(C(=O)c3ccccc3)c2c1</smiles><smiles></smiles><smiles>Cc1ccc(C)c(-n2nc3c(C)ccc(C)c3c2C(=O)PC(C)(C)C)c1</smiles><smiles>Cc1ccc(C(=O)c2c3cc(N)ccc3nn2-c2ccc([N+](=O)[O-])cc2)cc1</smiles><smiles></smiles>

84 e $(88 \%)$

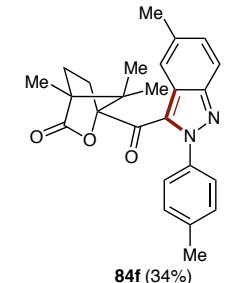

$84 f(34 \%)$

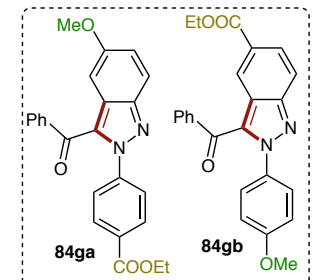

$84 \mathrm{ga} / 84 \mathrm{gb}=(1.8: 1$ ratio $), 56 \%$
Scheme 35: Rh-catalysed annulative coupling between azobenzenes and sulfoxonium ylides.

Mechanistic studies revealed that $\mathrm{C}-\mathrm{H}$ functionalization provided intermediate 85, which was transformed in a base-mediated intramolecular cyclization to the 1,3-dihydroindazole $\mathbf{8 6}$. Subsequent oxidation by either molecular oxygen or $\mathrm{Cu}(\mathrm{II})$ additives furnished the $(2 \mathrm{H})$-indazole $\mathbf{8 4}$ (Scheme 36$)$.
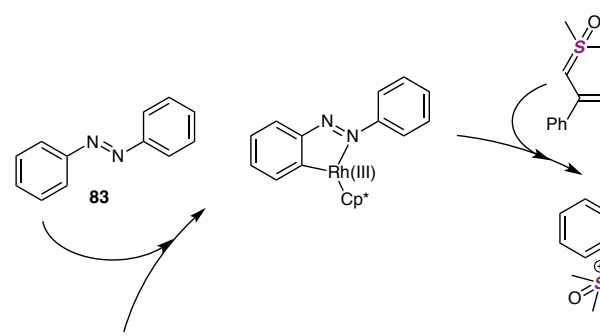

$\left[\mathrm{Cp}{ }^{*} \mathrm{Rh}(\mathrm{III}) \mathrm{OAc}\right] \mathrm{SbF}_{6}$

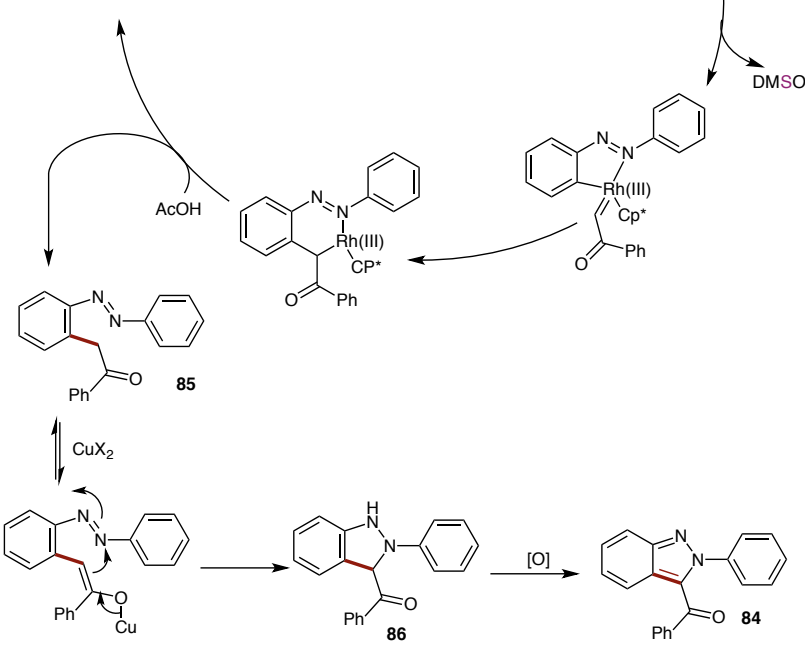

Scheme 36: Proposed mechanism for Rh-catalysed annulative coupling between Azobenzenes and sulfoxonium ylides

In early 2018, Cheng's group reported the transformation of ethyl benzimidates $\mathbf{8 7}$ into isoquinazolones $\mathbf{8 8}$ by a rhodium catalysed bis-2,6-ortho-C-H functionalization and annulation sequence using sulfoxonium ylide derived rhodium carbenoids (Scheme 37). ${ }^{56}$ Notably, this method has advantage that further removal of directing group is not required and it can be directly converted in situ to the final product $\mathbf{8 8}$. The isoquinazolones analogues prepared by this method had optoelectronic properties with absorption maxima around $340 \mathrm{~nm}$ and fluorescence maximum around $465 \mathrm{~nm}$. The optical properties were highly influenced by the substituents. In addition, the authors observed that 2-thiophenyl substituted isoquinazolones $\mathbf{8 8 b}$ had a Stokes shift as large as $141 \mathrm{~nm}$.
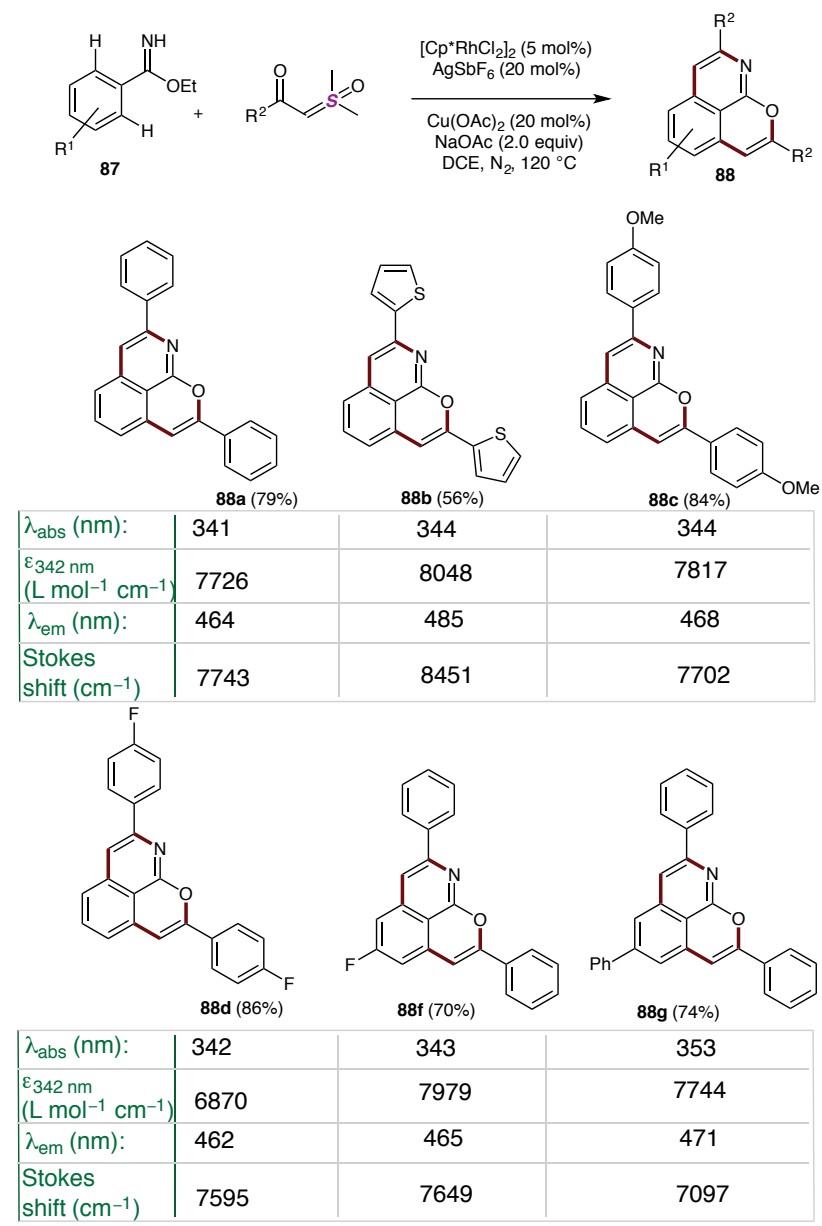

Scheme 37: Rh-catalysed annulative coupling between ethyl benzimidates and sulfoxonium ylides

Mechanistic explorations revealed that to activate both $\mathrm{C}-\mathrm{H}$ bonds of ethyl benzimidate $\mathbf{8 7}$, nitrogen atom only chelating to the rhodium catalyst rather than oxygen. Based on the proposed mechanism, initially ethyl benzimidate undergoes sequential carbenoid insertion via two catalytic cycles and the resulting intermediate $\mathbf{8 9 b}$ undergoes two annulations to provide isoquinazolones $\mathbf{8 8}$ (Scheme 38 ). 


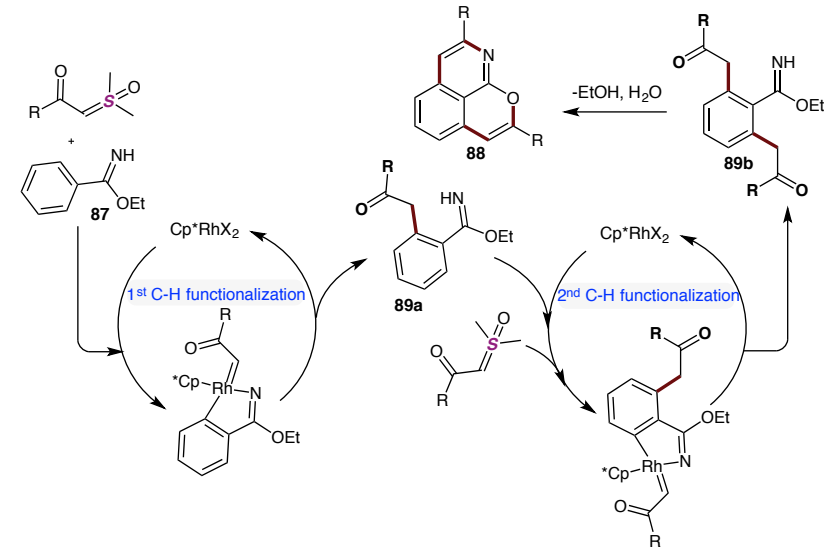

Scheme 38: Proposed mechanism for Rh-catalysed annulative coupling between ethyl benzimidates and sulfoxonium ylides

Very recently, Li's group reported a C-H activation of benzoylacetonitriles $\mathbf{9 0}$ and a subsequent reaction with sulfoxonium ylide derived rhodium carbenoids. This transformation allowed for the synthesis of a wide range of naphthols 91, 2,3-dihydronaphtho[1,8-bc]pyrans 92, and naphtho[1,8-bc]pyrans 93 in good yields (Scheme 39).57 Interestingly, addition of 1 equiv of water enhanced the yield of the reaction. The water may prevent catalyst poisoning by DMSO through stabilisation of the DMSO by-product through hydrogen bonding. If one of the ortho- $\mathrm{C}-\mathrm{H}$ positions of benzoylacetonitriles is blocked $\left(\mathrm{R}^{1} \neq \mathrm{H}\right)$, the coupling only afforded 1-naphthols. Importantly, the cyano group in the reacting partner 90 is necessary for this coupling and replacing it with acetyl, ester, and arenesulfonyl failed to proceed the reaction. Further, one-pot process of twofold C-H functionalization of $\mathbf{9 0}$ followed by acid mediated dehydration produced naphthopyrans 93.
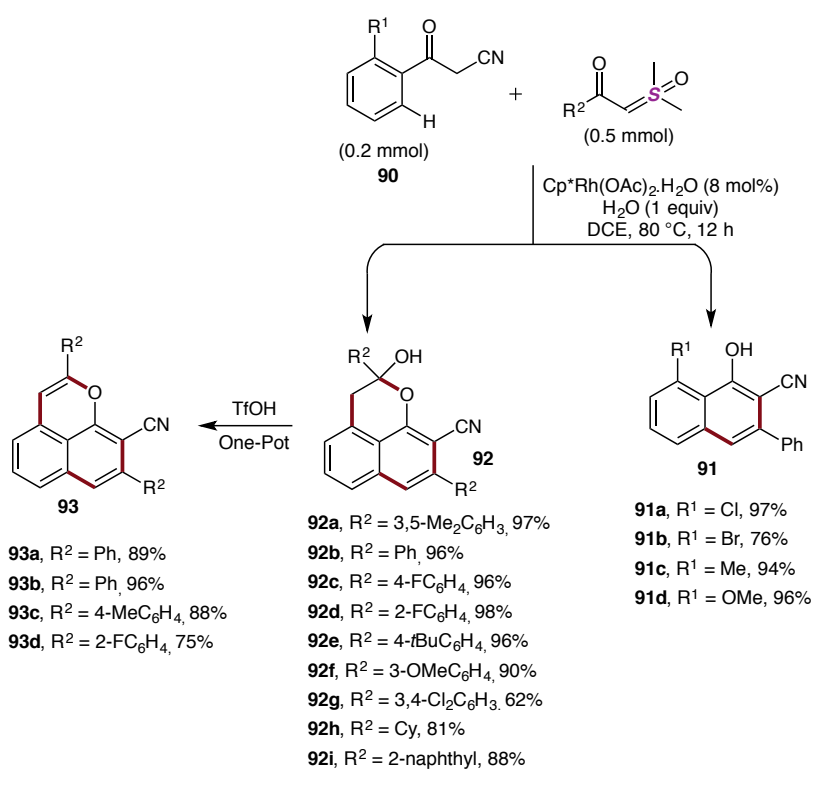

Scheme 39: Rh(III)-catalysed twofold C-H activation of benzoylacetonitriles

The authors proposed a mechanism proceeding through a Ccoordination-assisted ortho $\mathrm{C}-\mathrm{H}$ activation of benzoylacetonitrile $\mathbf{9 0}$ followed by formation of a rhodium carbenoid from the sulfoxonium ylide to give the rhodacyle 94a. Migratory insertion of the carbenoid into the rhodium-aryl bond and subsequent protonolysis provide $\mathbf{9 4 b}$ and cyclization lead to the 1-naphthol intermediate 91. Assisted by the naphthol -OH directing group, a second sequence of $\mathrm{C}-\mathrm{H}$ activation with carbenoid yield 2,3-dihydronaphtho[1,8-bc]pyrans 92 (Scheme 40).

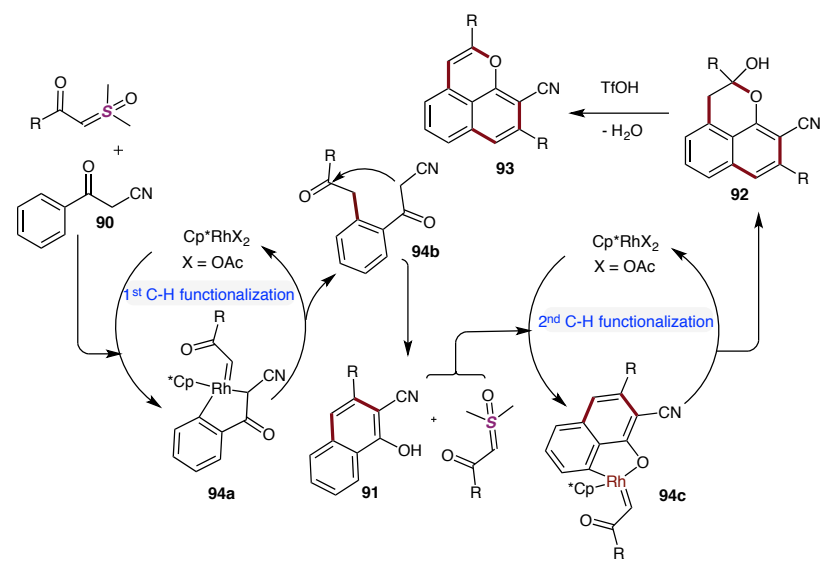

Scheme 40: Proposed mechanism for Rh(III)-catalysed twofold C-H activation of benzoylacetonitriles

Moreover, $\mathrm{Li}$ and coworkers developed a chemodivergent annulation between $N$-methoxybenzamides 99 and sulfoxonium ylide derived rhodium carbenoids (Scheme 41).58 In presence of Brønsted acid (PivOH, 2 equiv) the reaction provided isocoumarins 96, while the addition of Lewis acid ( $\mathrm{Zn}(\mathrm{OTf})_{2}, 0.5$ equiv) gave isoquinolones 97. The protocol was applied at 2 mmol scale for the synthesis of both isocoumarin and isoquinolone.

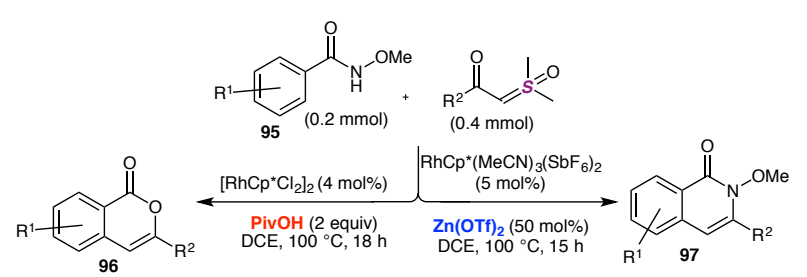

96a, $\mathrm{R}^{1}=\mathrm{H}, \mathrm{R}^{2}=\mathrm{Ph}, 90 \%$ $96 \mathrm{~b}, \mathrm{R}^{1}=4-\mathrm{ClC}_{6} \mathrm{H}_{4}, \mathrm{R}^{2}=\mathrm{Ph}, 93 \%$ $96 \mathrm{c}, \mathrm{R}^{1}=2-\mathrm{FC}_{6} \mathrm{H}_{4}, \mathrm{R}^{2}=\mathrm{Ph}, 91 \%$ 96d, $R^{1}=3-\mathrm{MeC}_{6} \mathrm{H}_{4}, \mathrm{R}^{2}=\mathrm{Ph}, 90 \%$ $96 e, R^{1}=\mathrm{H}, \mathrm{R}^{2}=4-\mathrm{BrC}_{6} \mathrm{H}_{4}, 89 \%$ 96f, $R^{1}=H, R^{2}=t B u, 80 \%$

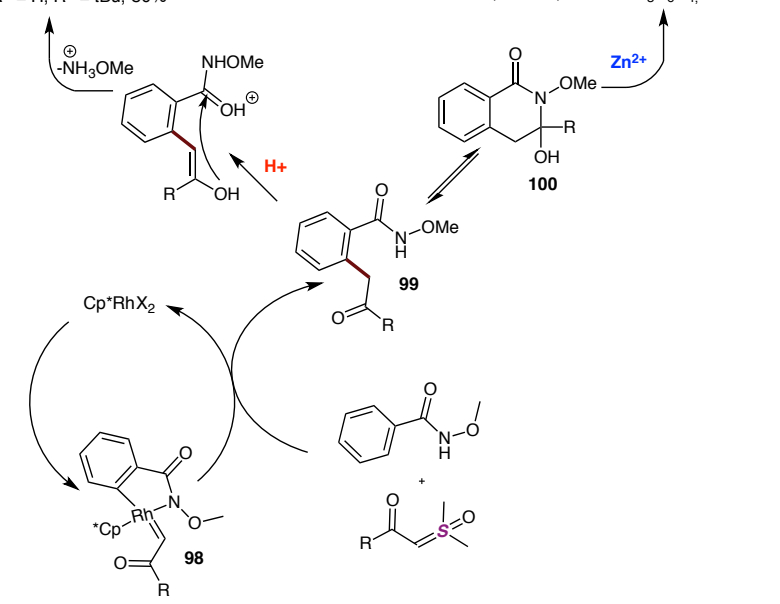

$97 \mathrm{a}, \mathrm{R}^{1}=\mathrm{H}, \mathrm{R}^{2}=\mathrm{Ph}, 95 \%$ 97b, $\mathrm{R}^{1}=4-\mathrm{ClC}_{0} \mathrm{H}_{4} \mathrm{R}^{2}=\mathrm{Ph}, 96 \%$ 97c, $\mathrm{R}^{1}=4-\mathrm{OMeC}_{6} \mathrm{H}_{4} \mathrm{R}^{2}=\mathrm{Ph}, 87 \%$ $97 \mathrm{~d}, \mathrm{R}^{1}=3-\mathrm{MeC}_{6} \mathrm{H}_{4} \mathrm{R}^{2}=\mathrm{Ph}, 78 \%$ 97e $\mathrm{R}^{1}=\mathrm{H}^{2} \mathrm{R}^{2}=4 \mathrm{Cr}^{2} \mathrm{H}_{4} 8 \%$ 97f, $\mathrm{R}^{1}=\mathrm{H}^{2} \mathrm{R}^{2}=4-\mathrm{CF}_{3} \mathrm{C}_{4}, \mathrm{H}_{4}, 75 \%$

Scheme 41: Rh-catalysed chemodivergent annulations between $\mathrm{N}-$ methoxybenzamides and sulfoxonium ylides

According to the proposed mechanism (Scheme 41), the $\mathrm{N}$ methoxy group of 95 direct the rhodium ortho- $\mathrm{C}-\mathrm{H}$ insertion followed by formation of the sulfoxonium ylide derived carbenoid 98, which upon insertion of the carbenoid provides 99. 
The resulting intermediate 99 is lactonized with the elimination of $\mathrm{NH}_{2} \mathrm{OMe}$ in the presence of pivalic acid leading to 96 . In contrast, $\mathrm{Zn}(\mathrm{OTf})_{2}$ additive together with the more Lewis acidic cationic Rh(III) catalyst, selectively activates the ketone carbonyl so that the nucleophilic attack of the amide nitrogen affords the lactamization product 97 upon dehydration.

\section{Polymerization of carbenoids generated from sulfoxonium ylides}

To date, there is one report on the metal-catalysed polymerization of sulfoxonium ylides. In 2012, Bruin and coworkers reported a polymer synthesis using sulfoxonium ylides as monomers under rhodium catalysis (Scheme 42).59 Dimethyl sulfoxonium methylide $\mathbf{1}$ was used as a one carbon metal carbenoid synthon $\left(\mathrm{M}=\mathrm{CH}_{2}\right)$ for the generation of polymethylene compound 101. Moreover, the co-polymerization of sulfoxonium ylides with diazo compounds in the presence of rhodium catalysts generated a unique diblock copolymer 102. Substituted sulfoxonium ylides 103 and 104 could not be polymerized, probably because of steric hindrance. The carbenoid polymerization reaction was found quite specific for rhodium catalysts and other catalysts such as iridium(I), palladium(0) and palladium(II) complexes gave very poor results under similar reaction conditions.
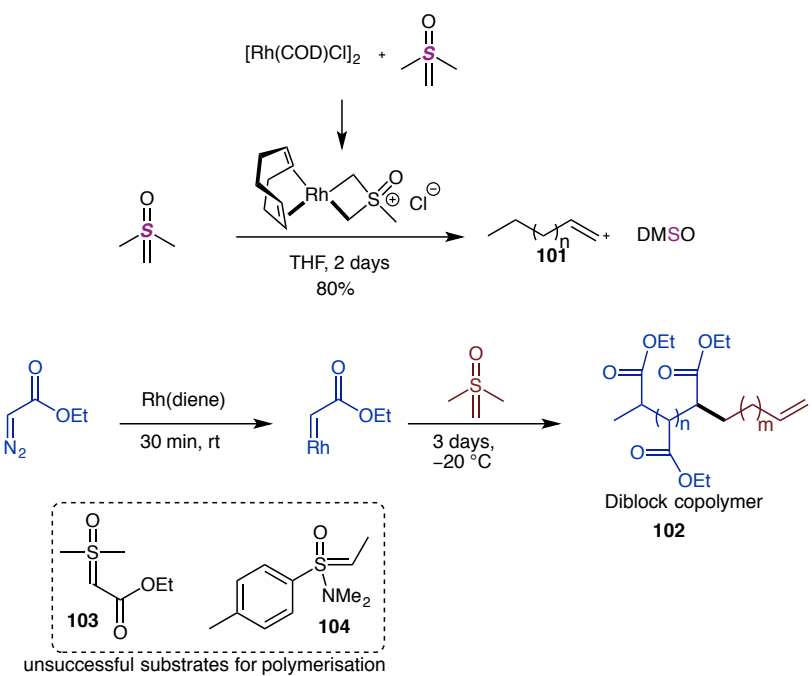

102

Scheme 42: Rh-catalysed polymerization of sulfoxonium ylide

\section{Conclusion and Perspective}

Since 2009, progressive breakthroughs in the use of sulfoxonium ylides as versatile carbenoid precursors in $\mathrm{X}-\mathrm{H}(\mathrm{X}=\mathrm{C}, \mathrm{N}, \mathrm{O}, \mathrm{S})$ insertion reactions have been reported. Many of the sulfoxonium ylides are bench stable crystalline compounds and a safe carbenoid source for bulk-scale reactions. In addition, these reagents are precursors for mono-substituted carbenoids ( $\mathrm{M}=\mathrm{CHR}$ ), while mono-substituted diazo compounds are hardly applicable in many of the carbenoid transfer $\mathrm{C}-\mathrm{H}$ insertion reactions. However, numerous challenges remain to be solved in order to expand the scope of sulfoxonium ylide derived carbenoids. First, metal-catalysed transformations of sulfoxonium ylides are limited to insertion reactions and other carbenoid transfer reactions such as cyclopropanations and dipolar cycloadditions have not been reported. Second, the generation of carbenoids from sulfoxonium ylides requires precious metal-based catalysts such as rhodium, iridium, ruthenium, gold and platinum complexes, while more economic and environmentally friendly metal alternatives such as iron and copper catalysts have not been described. Third, metal-catalysed sulfoxonium ylide chemistry for carbenoid transfer reactions has not been investigated beyond $\alpha$-keto sulfoxonium ylides and there is still much room for the development of structurally more diverse sulfoxonium ylides to expand the breadth of their chemistry. Finally, the design of an enantioselective sulfoxonium ylide derived carbenoid transformation still remains an elusive goal.

\section{Funding Information}

We thank Research Council of Norway (FRINATEK Grant No. 231706 and Centre of Excellence Grant No. 262695), the Tromsø Research Foundation (Grant No. TFS2016KHH) and Notur - The Norwegian Metacenter for Computational Science (CPU Grant No. nn9330k). J.V. thanks CHOCO-UiT (https://site.uit.no/choco/) research team (PI: Kathrin H. Hopmann) for research and financial support.

\section{References:}

(1) (a) Dötz, K. H., Angew. Chem. Int. Ed. 1984, 23, 587. (b) Doyle, M. P.; Forbes, D. C., Chem. Rev. 1998, 98, 911.

(2) (a) Brookhart, M.; Studabaker, W. B., Chem. Rev. 1987, 87, 411. (b) Davies, H. M. L.; Huby, N. J. S.; Cantrell, W. R.; Olive, J. L., J. Am. Chem. Soc. 1993, 115, 9468.

(3) (a) Xu, X.; D oyle, M. P., Acc. Chem. Res. 2014, 47, 1396. (b) Davies, H. M. L., Curr. Org. Chem. 1998, 2, 463.

(4) Zhu, S.-F.; Zhou, Q.-L., Acc. Chem. Res. 2012, 45, 1365

(5) (a) Guo, X.; Hu, W., Acc. Chem. Res. 2013, 46, 2427. (b) Zhang, Y.; Wang, J., Coord. Chem. Rev. 2010, 254, 941.

(6) Liu, Z.; Wang, J., J. Org. Chem. 2013, 78, 10024.

(7) (a) Ye, T.; McKervey, M. A., Chem. Rev. 1994, 94, 1091. (b) Zhang, Z.; Wang, J., Tetrahedron 2008, 64, 6577. (c) Zhang, Y.; Wang, J., Chem. Commun. 2009. (d) Ford, A.; Miel, H.; Ring, A.; Slattery, C. N.; Maguire, A R.; McKervey, M. A., Chem. Rev. 2015, 115, 9981.

(8) (a) Moore, J. A.; Ree, D. E., Org. Synth. 1961, 41, 16. (b) Bio, M. M.; Javadi, G.; Song, Z. J., Synthesis 2005, 19. (c) Proctor, L. D.; Warr, A. J., Org. Process Res. Dev. 2002, 6, 884.

(9) Jia, M.; Ma, S., Angew. Chem. Int. Ed. 2016, 55, 9134.

(10) Burtoloso, A. C. B.; Dias, R. M. P.; Leonarczyk, I. A., Eur. J. Org. Chem. 2013, 2013, 5005.

(11) Trost, B. M.; Melvin, L. S., 1975, Sulfur Ylides: Emerging Synthetic Intermediates, Academic Press New York.

(12) Baldwin, J. E.; Adlington, R. M.; Godfrey, C. R. A.; Gollins, D. W.; Vaughan, J. G., J. Chem. Soc., Chem. Commun. 1993, 1434.

(13) Corey, E. J.; Chaykovsky, M., J. Am. Chem. Soc. 1962, 84, 867.

(14) Corey, E. J.; Chaykovsky, M., J. Am. Chem. Soc. 1964, 86, 1640.

(15) (a) Johnson, C. R.; Haake, M.; Schroeck, C. W., J. Am. Chem. Soc. 1970, 92, 6594. (b) Johnson, C. R.; Rogers, P. E., J. Org. Chem. 1973, 38, 1798. (c) Johnson, C. R.; Janiga, E. R.; Haake, M., J. Am. Chem. Soc. 1968, 90, 3890. (16) Nozaki, H.; Tunemoto, D.; Matubara, S.; Kondô, K., Tetrahedron 1967, 23, 545 .

(17) Baldwin, J. E.; Adlington, R. M.; Godfrey, C. R. A.; Gollins, D. W.; Smith, M. L.; Russel, A. T., Synlett 1993, 1993, 51.

(18) Kaiser, C.; Trost, B. M.; Beeson, J.; Weinstock, J., J. Org. Chem. 1965, 30, 3972 .

(19) Ide, J.; Kishida, Y., Tetrahedron Lett. 1966, 7, 1787.

(20) Tamura, Y.; Miyamoto, T.; Nishimura, T.; Eiho, J.; Kita, Y., J. Chem. Soc., Perkin Trans. 1 1974, 102.

(21) Bradbury, R. H.; Gilchrist, T. L.; Rees, C. W., J. Chem. Soc., Perkin Trans. 1 1981, 3225 .

(22) Marino, J. P.; Kaneko, T., J. Org. Chem. 1974, 39, 3175.

(23) Tamuru, Y.; Miyamoto, T.; Kiyokawa, H.; Kita, Y., J. Chem. Soc., Perkin Trans. 1 1974, 1125.

(24) Faragher, R.; Gilchrist, T. L., J. Chem. Soc., Perkin Trans. 1 1977, 1196. (25) Yamanaka, H.; Konno, S.; Sakamoto, T.; Niitsuma, S.; Noji, S., Chem. Pharm. Bull. 1981, 29, 2837.

(26) Yamanaka, H.; Niitsuma, S.; Sakamoto, T., Heterocycles 1978, 10.

(27) Ando, W.; Yagihara, T.; Tozune, S.; Nakaido, S.; Migita, T., Tetrahedron Lett. 1969, 10, 1979.

(28) Dost, F.; Gosselck, J., Tetrahedron Lett. 1970, 11, 5091.

(29) Moody, C. J.; Slawin, A. M. Z.; Taylor, R. J.; Williams, D. J., Tetrahedron Lett. 1988, 29, 6009.

(30) Zhu, C.; Yoshimura, A.; Ji, L.; Wei, Y.; Nemykin, V. N.; Zhdankin, V. V., Org. Lett. 2012, 14, 3170. 
(31) Vaitla, J.; Hopmann, K. H.; Bayer, A., Org. Lett. 2017, 19, 6688. (32) Mangion, I. K.; Nwamba, I. K.; Shevlin, M.; Huffman, M. A., Org. Lett. 2009, 11, 3566.

(33) Vaitla, J.; Bayer, A.; Hopmann, K. H., Angew. Chem. Int. Ed. 2017, 56, 4277.

(34) Baratta, W.; Zotto, A. D., Chem. Commun. 1997, 2163.

(35)A. K. Yudin, Catalyzed Carbon-Heteroatom Bond Formation; WileyVCH: Weinheim, Germany, 2011.

(36)M. P. Doyle, M. A. McKervey, T. Ye, Modern Catalytic Methods for Organic Synthesis with Diazo Compounds; Wiley: New York, 1998;

(37) Trost, B. M., J. Am. Chem. Soc. 1967, 89, 138.

(38) Cohen, T.; Herman, G.; Chapman, T. M.; Kuhn, D., J. Am. Chem. Soc. 1974, 96, 5627.

(39) Cimetière, B.; Julia, M., Synlett 1991, 1991, 271.

(40) Mangion, I. K.; Weisel, M., Tetrahedron Lett. 2010, 51, 5490.

(41) Mangion, I. K.; Ruck, R. T.; Rivera, N.; Huffman, M. A.; Shevlin, M., Org. Lett. 2011, 13, 5480 .

(42) Molinaro, C.; Bulger, P. G.; Lee, E. E.; Kosjek, B.; Lau, S.; Gauvreau, D.; Howard, M. E.; Wallace, D. J.; O'Shea, P. D., J. Org. Chem. 2012, 77, 2299.

(43) Phelps, A. M.; Chan, V. S.; Napolitano, J. G.; Krabbe, S. W.; Schomaker, J. M.; Shekhar, S., J. Org. Chem. 2016, 81, 4158.

(44) Cheng, J.; Wu, X.; Sun, S.; Yu, J.-T., Synlett 2018 (doi:10.1055/s-00371610263).

(45) Eberlin, M. N.; Kascheres, C., J. Org. Chem. 1988, 53, 2084.

(46) Barday, M.; Janot, C.; Halcovitch, N. R.; Muir, J.; Aissa, C., Angew. Chem. Int. Ed. 2017, 56, 13117.

(47) Xu, Y.; Zhou, X.; Zheng, G.; Li, X., Org. Lett. 2017, 19, 5256.

(48) Xu, Y.; Yang, X.; Zhou, X.; Kong, L.; Li, X., Org. Lett. 2017, 19, 4307.

(49) Zheng, G.; Tian, M.; Xu, Y.; Chen, X.; Li, X., Org. Chem. Front. 2018, 5, 998.

(50) Cheng, J.; Yang, R.; Wu, X.; Sun, S.; Yu, J.-T., Synthesis 2018, 50, 3487.

(51) Xie, H.; Lan, J.; Gui, J.; Chen, F.; Jiang, H.; Zeng, W., Adv. Synth. Catal. 2018, 360, 3534 .
(52) Chen, G.; Zhang, X.; Jia, R.; Li, B.; Fan, X., Adv. Synth. Catal. 2018, 360, 3781 .

(53) Halskov, K. S.; Witten, M. R.; Hoang, G. L.; Mercado, B. Q.; Ellman, J. A., Org. Lett. 2018, 20, 2464.

(54) Hoang, G. L.; Ellman, J. A., Tetrahedron 2018, 74, 3318.

(55) (a) Oh, H.; Han, S.; Pandey, A. K.; Han, S. H.; Mishra, N. K.; Kim, S.; Chun, R.; Kim, H. S.; Park, J.; Kim, I. S., J. Org. Chem. 2018, 83, 4070. (b) Zhu, J.; Sun, S.; Cheng, J., Tetrahedron Lett. 2018, 59, 2284.

(56) Wu, X.; Xiong, H.; Sun, S.; Cheng, J., Org. Lett. 2018, 20, 1396.

(57) Hu, P.; Zhang, Y.; Xu, Y.; Yang, S.; Liu, B.; Li, X., Org. Lett. 2018, 20, 2160 .

(58) Xu, Y.; Zheng, G.; Yang, X.; Li, X., Chem. Commun. 2018, 54, 670.

(59) Suarez, A. I. O.; del Río, M. P.; Remerie, K.; Reek, J. N. H.; de Bruin, B., ACS Catal. 2012, 2, 2046.

\section{Biosketches}

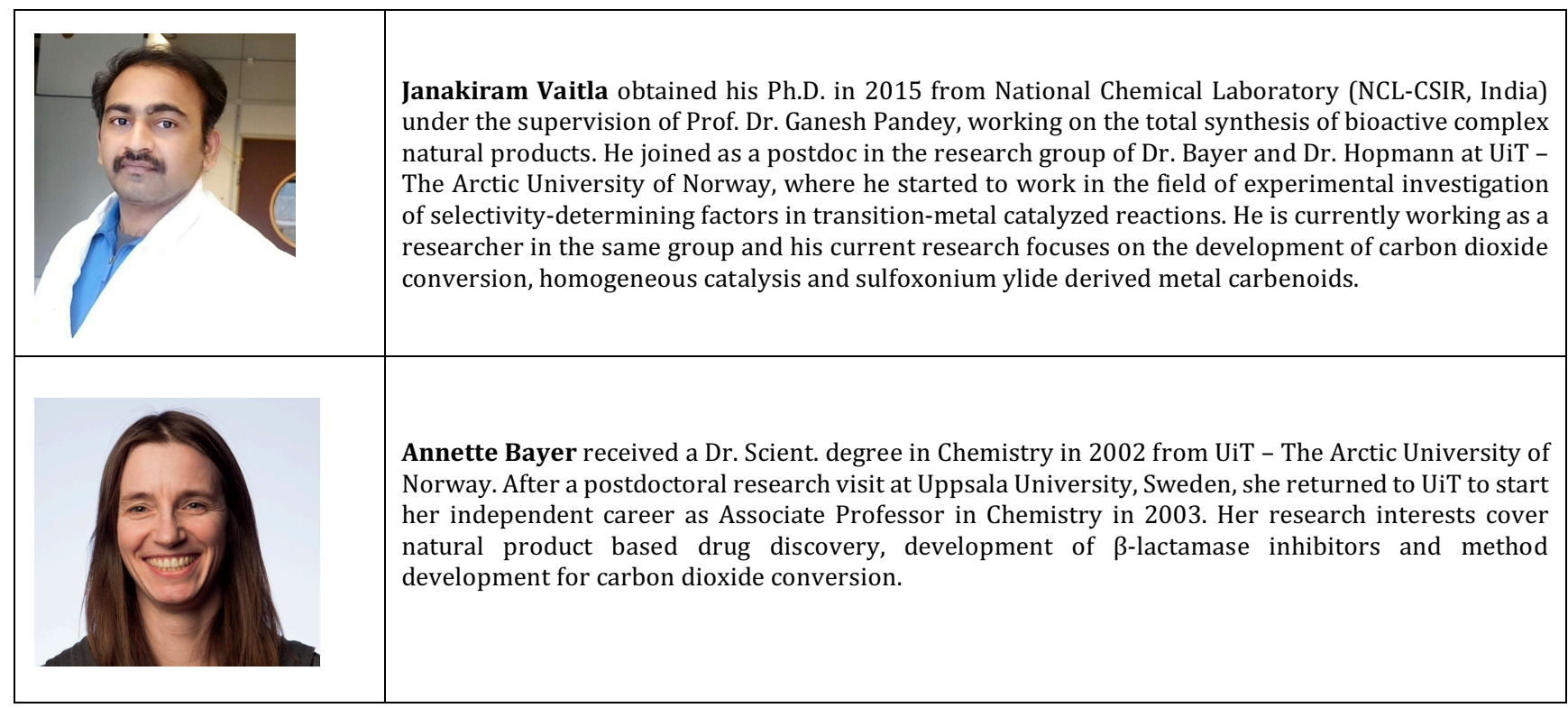

